\title{
Marcos o la corrección de una ideología triunfalista. \\ Pautas para la lectura de un evangelio beligerante y comprometido.
}

\author{
XAVIER ALEGRE, \\ Sant Cugat del Vallés, Barcelona. \\ Centro de Reflexión Teológica, San Salvador.
}

\section{Introducción}

Según una tradición muy antigua, el evangelio de Marcos fue escrito en Roma pocos años después de que la Iglesia, a la cual iba dirigida la obra, hubiera experimentado en carne propia la persecución por parte de Nerón. Según la tradición, en ella murieron dos grandes columnas de la Iglesia, Pedro y Pablo. Viviendo en El Salvador, una Iglesia marcada por una dura persecución y regada por la sangre de muchísimos mártires, entre los que destaca Mons. Oscar A. Romero - San Romero de América, como le denomina Mons. Casaldáliga ${ }^{1}$, me ha resultado más diáfano el tenor que Marcos quiso dar a su obra. Por eso el presente artículo, que recoge, en lo fundamental, una conferencia que di a profesores de la Universidad de Barcelona, quisiera ser un homenaje de gratitud a las comunidades cristianas de El Salvador, sobre todo a sus gentes sencillas y pobres, los auténticos destinatarios de una obra como la de Marcos, que con su testimonio de fe, esperanza y amor me han enseñado a leer con ojos nuevos el evangelio de Jesús, muerto y resucitado por haber vivido en toda su radicalidad la solidaridad con los pobres, como testimonio del amor infinito de Dios Padre.

\section{Un evangelio durante mucho tiempo olvidado injustamente}

Durante mucho tiempo el evangelio de Marcos ha sido "la cenicienta" de los evangelios. Al lado de evangelios como el de Mateo y el de Lucas que tienen una proyección eclesial fácilmente constatable, o el de Juan, considerado por muchos como el evangelio "espiritual" por excelencia, Marcos parecía poco interesante. No se descubria en él una personalidad propia, suficientemente acentuada. Incluso un hombre tan extraordinario como san Agustín es, en parte, responsable de dicha infravaloración al afirmar que Marcos es un simple resumen de Mateo. ${ }^{2}$ Se comprende, entonces, que desde esta perspectiva ni los especialistas, ni les comunidades cristianas antes de la reforma de los textos litúrgicos, tuviesen especial interés en conocer el pensamiento de Marcos. 
Por suerte esta situacion ha cambiado radicalmente en los últimos años. Las razones de este cambio pueden reducirse, fundamentalmente, a dos. En primer lugar -y por razones que me parecen convincentes- la mayoria de los especialistas es hoy del parecer que Marcos es el más antiguo de los evangelios ${ }^{3}$ y que su texto fue empleado por Mateo y Lucas al componer sus evangelios. ${ }^{4}$ En segundo lugar - y gracias, sobre todo, a los autores que han empleado el método exegético denominado "historia de la redacción"s se ha ido descubriendo, cada vez más, que los redactores de los evangelios deben ser considerados como auténticos "autores" y no como meros "recopiladores" de tradiciones más antiguas. 6 En efecto, el análisis de los evangelios muestra que los evangelistas no se limitaron a empalmar las Iradiciones que habian recibido, sino que, como teólogos con personalidad propia, dieron su sello tanto al material de la tradición como a la obra que escribieron. La linguistica moderna y los estudios literarios más recientes, al subrayar que en una obra "el tono está antes que las partes" y que un texto concreto debe ser comprendido desde el conjunto de la obra, ${ }^{7}$ han contribuido a que se valore más la tarea propia de cada evangelista.

A estas dos razones que han contribuido a que se descubriera mejor la personalidad teológica de Marcos, podemos affadir una tercera, no menos importante y fácil de entender, sobre todo en un continente como el latinoamericano donde las comunidades cristianas se ven confrontadas a diario con los enormes problemas que plantea la injusticia que domina el mundo, una injusticia que no permite que los pobres puedan vivir de un modo digno y humano. Pues es precisamente Marcos el evangetista que nos presenta la figura de Jesús y de la comunidad cristiana con los rasgos más críticos hacia determinadas presentaciones triunfalistas de la fe que olvidan el conflicto histórico de Jesús con los poderes fácticos, políticos y religiosos de su tiempo. Por eso la teología de la liberación ha podido sintonizar tan fácilmente con él. En este sentido, Marcos vuelve a ser muy actual, porque interpela a las conciencias cristianas demasiado "instaladas."

\section{La obra de Marcos: una "buena noticia"}

Antes de desarrollar el tema, quiero hacer, sin embargo, una observacion fundamental que, por otro lado, parece hoy obvia a los intérpretes del N.T. En Marcos no vamos a encontrar una historia de Jesús en el sentido técnico que esta palabra tiene para nosotros, 9 sino un "evangelio," es decir, una "buena noticia." Se trata de un género literario creado por Marcos 10 para dar testimonio e interpretar auténticamente la figura de Jesús de Nazaret, muerto y resucitado, "maestro" único (cf. 1,22.27) y definitivo de la comunidad a la cual el autor dedica su obra. Estamos, pues, delante de un texto, de una obra literaria que recoge distintas tradiciones sobre Jesús y que emplea diversas formas literarias. 11 El evangelio de Marcos, por tanto, debe ser leido desde esta bptica y no desde el punto de vista primariamente histórico. En otras palabras: cuando leemos un fragmento de Marcos no nos podemos colocar nunca directamente en la historia que se nos narra en él (no se trata de un video), sino que debemos 
situarnos primero en el texto. Pues tanto delante de la obra en su conjunto como de un fragmento en particular, debemos preguntarnos, ante todo, cuál es la clave de lectura adecuada que nos permitirá comprender el texto en su sentido original pretendido por el autor. Sólo si el género literario del texto en cuestión lo permite, podremos, en un segundo paso, intentar descubrir que es lo que pudo haber de histórico, en sentido moderno, en el hecho o en la palabra de Jesús que Marcos, iluminado por la fe pascual, nos cuenta en su evangelio.

\section{Marcos y su comunidad}

Por último quisiera explicar en esta introducción qué es lo que me ha llevado a dar a mi artículo el título de "Marcos o la corrección de una ideología triunfalista." Este título presupone que estoy convencido, por mis estudios sobre Marcos 12 de que el autor no es un teólogo desencarnado que, desde la mesa de su escritorio, explica, por curiosidad intelectual y tras una minuciosa investigación histórica, quién fue el personaje Jesús de Nazaret. Más bien creo que Marcos escribió su obra pensando primariamente en su comunidad -una comunidad que tiene un rostro bien concreto ${ }^{13}-$ a fin de ayudarle a vivir mejor su fe en Jesús.

Este hecho no tiene por qué sorprendernos, pues ya las tradiciones que él recoge habian sido conservadas y acuntadas por hombres que se hablan propuesto, como tarea fundamental, fundar y estimar a las comunidades cristianas que ellos iban creando.

De hecho, mirando los acentos que Marcos pone en su obra, ${ }^{14}$ se llega a la conclusión de que escribió su evangelio porque creia que su comunidad estaba en peligro de desfigurar la imagen de Jesús, pues no había entendido bien cuál era el núcleo o la esencia radical de su persona. Si queremos llegar al corazón de lo que preocupaba a Marcos, podríamos decir que estaba convencido de que la raiz última del mal que amenazaba a su comunided - probablemente sin que ella misma cayera en la cuenta de ello- estaba en la interpretación triunfalista de la figura de Jesús, una interpretación que podía sentirse apoyada por el poder de hacer milagros que era propio de Jesús. ${ }^{15}$

¿En qué me baso para interpretar asi la intención de Marcos? De hecho se me podría objetar que, al margen de Marcos, no disponemos de ningún testimonio contemporáneo ${ }^{16}$ que nos informe sobre el motivo que lo llevó a escribir su obra, ni el autor encabeza su obra con un prólogo semejante al de Lucas 1,1-4. ¿Cómo podemos saber, entonces, qué es lo que le preocupaba a Mar$\cos ?$

La dificultad no es tan grave como a primera vista podría parecer. Pues, de hecho, el texto de Marcos es lo suficientemente largo y "personal" como para que podamos deducir cuál fue la intención del autor. Precisamente para poder descubrir dicha intención, intentaré fundamentar mi tesis con ayuda de dos elementos tipicamente redaccionales -es decir, propios del redactor del evangelio- que son muy significativos para la comprensión de la obra. En primer lugar, analizare la estruetura que Marcos dio a su obra. ${ }^{17}$ En segundo lu- 
gar, presentaré unos retoques redaccionales que él realiza, de modo sistemático - sobre todo en los milagros y exorcismos y en los textos en los cuales aparecen los discípulos de Jesús-- en sus fuentes y que tienen como común denominador lo que los especialistas han convenido en llamar "el secreto mesiánico" y "la incomprensión de los discipulos."

\section{Parte primera: la estructura del evangelio de Marcos}

\section{Introducción}

La mayoria de los especialistas está hoy de acuerdo en que la estructura de Marcos es, fundamentalmente, obra del evangelista. El análisis de dicha estructura, por tanto, puede ayudarnos a descubrir cuál era la intención teológica primordial que guió a Marcos en la redacción de su obra. ${ }^{19}$ Pero, icómo se puede descubrir dicha estructura si el autor no nos la indica explicitamente?20

Dos tipos de indicios en el texto - literarios y de contenido- nos dan pistas para poder descubrir la estructura interna de Marcos. La coincidencia de dichos criterios me lleva a creer que la estructura del evangelio que propongo responde efectivamente a la intención original de Marcos y puede servir, por tanto, para desentrañar el pensamiento teológico del autor.

\section{La pregunta fundamental de Marcos}

La cuestión central de Marcos se puede condensar en la pregunta: ¿quién es Jesús? Esta pregunta se encuentra expllcitamente en una pericopa tan central y decisiva para poder comprender la lógica que se encuentra detrás de la estructura de Marcos, como lo es la de la confesión de Pedro $(8,27 s s$.$) . Ella$ nos puede servir de hilo conductor en el camino que nos conduzca al descubrimiento del pensamiento teológico del evangelista.

Pero Marcos no se formula esta pregunta de un modo abstracto, desencadenado, sino que la ve íntimamente relacionada con la cuestión de quién es el verdadero discípulo de Jesús. ${ }^{21}$ Pues, para él - la atención continua que dedica a los discípulos y la manera como los presenta en su obra nos lo manifestará bien a las claras-, el cristiano no se puede preguntar quién es Jesús sin preguntarse, a la vez, cuál es su actitud concreta ante este personaje histórico que se manifestó con unos rasgos tan escandalosos para los poderes políticos de su época, ya que fueron precisamente los que se creian "piadosos" - sobre todo los responsables de la comunidad judia en sus distintos niveles 22 , en alianza con los políticos (cf. 3,6 y el relato de la pasión: cap. 14-15), quienes lo llevaron a la cruz.

\section{El drama de Jesús}

Para poder saber quién es Jesús, hay que saber por qué lo mataron. El conflicto de Jesús con las fuerzas religiosas, económicas y politicas de su tiem- 
po no es, para Marcos, más que la parte visible del iceberg contra el que chocó el crucificado. En el fondo, toda la vida de Jesús no es sino un drama -y como tal la presenta Marcos en su obra. Pero un drama con unas raices muy profundas. Pues la hisıoria de Jesús que se desarrolló en Galilea, en la Decápolis y en Jerusalén es el escenario de la lucha escatológica entre Dios y las fuerzas del mal personificado, según la mentalidad de la época, en el demonio. El inicio de esta lucha lo presenta Marcos programáticamente en el relato de las tentaciones de Jesús $(1,12 \mathrm{~s}$.).23 Las curaciones, las discusiones y, sobre todo, los exorcismos que en Marcos ocupan un lugar proporcionalmente más amplio que en los otros evangelios, son la continuación y el exponente de esta lucha a muerte entre Jesús y los poderes del mal. La pasión y la muerte de Jesús serán la culminación del drama: por un lado, revelarán aquello de lo que son capaces los enemigos de Dios con tal de conseguir acallar la voz del Hijo del dueño de la viña ( = el Hijo de Dios) quien les reclamaba los frutos de la cosecha del Padre (cf. 12,1-12); pero, por olro, comportará también, de modo paradójico, el triunfo de Jesús (cf. 15,39; 16,6s.), un triunfo anticipado ya en los exorcismos de Jesús que muestran a la comunidad - una comunidad perseguida, la cual se ve amenazada también por las fuerzas del mal (cf. 13,9-13)- que Jesús ha vencido al espíritu impuro (cf. 1,21-28; 5,1-20; 9,14-29; también 1,34.39; $3,115.15-22 ; 6,7 b .13) .{ }^{24}$

Al mismo tiempo, Marcos tiene interés por mostrar a su comunidad cuál es la raíz última del conflicto que enfrentó a Jesús con los poderes políticos, económicos y religiosos de su época: su predicación del reinado de Dios (por esto la sitúa, programáticamente, al inicio de su actividad pública: 1.145.$)^{25}$ la cual implicó una clara opción en favor de los pobres por parte de Jesús como revelación de la lógica del amor gratuito y universal de Dios. Hasta qué punto la predicación del reino por parte de Jesús tuvo que resultar conflictiva y peligrosa para los poderes políticos y religiosos que no se basan en la lógica de Dios (cf. la critica que les hace Marcos como lección para su comunidad en 10,42-45), quiso ejemplificarlo, ya de entrada, en el primer bloque de milagros (cf. 1,20-45) y de controversias (cf. 2,1-3,5), con los cuales explicita el significado de la cercania del reinado de Dios, anunciada por Jesús, y de la conversión que se nos exige a todos con este motivo en 1,14-15. Pues en este bloque inicial de su evangelio - y el resto de la obra no hará sino confirmar esta presentación inicial- aparece la razón fundamental que llevo a los hombres religiosos de Israel (los fariseos) y a los politicos (los partidarios de Herodes) a confabularse para poder matar a Jesús (cf. 3,6). El motivo es, en el fondo, bien sencillo y aparece formulado claramente en el último episodio del fragmento. El conflicto le vino a Jesús por el modo cómo hablaba y hacía presente a Dios en el mundo, pues la radicalidad con que Jesús mostraba que la máxima gloria de Dios y, por tanto, su voluntad imperativa, era el bien del hombre (la pregunta decisiva y definitiva que tiene que hacerse todo hombre religioso para saber si le es licito hacer algo o no, es el bien del hombre: $\mathrm{cf} .3,4$ ), hasta el punto de que cualquier otro precepto religioso -iincluso el guardar el sábado, uno de los preceptos más sagrados para los israelitas piadosos de la época de Jesús! - estuviera subordinado al bien, a la vida del hombre ("el sábado está

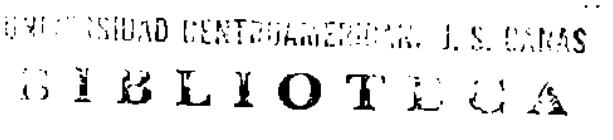


hecho para el hombre y no el hombre para el sábado," leemos inmediatamente antes en 2,27), no podía menos de entrar en conflicto con los hombres que se creian piadosos 26 y con los políticos, aunque ello ocurriera por motivos distintos.

Marcos quiere, en último término, que, a la luz del conflicto histórico que desencadenó la manera concreta cómo Jesús hizo presente cl reinado de Dios entre los hombres, se descubra hasta qué punto "el conflicto" es inherente a toda opción de vida cristiana que se tome suficientemente en serio el seguimiento de Jesús de Nazaret. Por este motivo tiene mucho interés en estructurar de tal manera su obra, que el lector pueda captar las coordenadas fundamentales que enmarcan las tradiciones jesuánicas que él quiere transmitir a su comunidad y que, al captarlas, se sienta llamado a una conversión radical de su vida, tal como pide Jesús al iniciar su misión (cf. 1,14s).

\section{Estructura teológica y narrativa de Marcos}

Teniendo en cuenta que la obra original del autor que llamamos Marcos termina en 16,827 y que a partir de 8,27 Jesús empieza a revelarse de una manera radicalmente nueva (cf. 8,31), ${ }^{28}$ podemos estructurar el evangelio en dos partes $(1,14-8,26$ y $8,27-16,8)$ las cuales van precedidas por el prólogo de la obra. Esta incluye el título (1,1: "comienzo del evangelio de Jesús, el Mesías, Hijo de Dios"29) y las narraciones teológicas que hablan de Juan Bautista, el precursor $(1,2-8)$, del bautismo $(1,9-11)$ y de las tentaciones de Jesús $(1,12-13)$. La estructura que propongo creo que es la que mejor refleja la intención original de Marcos. ${ }^{30}$

Introducclón $(1,1-13)$

Título $(1,1)$

Juan Bautista $(1,2-8)$

Bautismo de Jesús (1,9-11)

Tentaciones de Jesús $(1,12-13)$

Primera parte: el misterio de la mesianidad de Jesús se revela progresivamente $(1,14-8,26)$

1) Poder de Jesús - ceguera de los fariseos y herodianos $(1,14-3,6)$

a) Sumario de la predicación del evangelio $(1,14-15)$ Vocación de los primeros discipulos $(1,16-20)$

b) Jesús enseffa y cura con poder $(1,21-45)$ Controversias con los fariseos $(2,1-3,5)$

c) Ceguera de los fariseos y herodianos $(3,6)$

2) Revelación de Jesús en palabras y signos - ceguera de los judíos (3,7-6,6s)

a) Sumario de curaciones y exorcismos $(3,7-12)$ Institucion de los Doce $(3,13-19)$

b) Opiniones equivocadas sobre Jesús: incomprensión de la familia de Jesús 
y de los escribas $(3,20-35)$

Tres parábolas $(4,1-34)$ y tres milagros $(4,35-5,43)$

c) Ceguera de los conciudadanos de Jesús (6,1-6a)

3) Jesús prepara a los discípulos - ceguera de los discípulos $(6,6 \mathrm{~b}-8,26)$

a) Sumario de la eseñanza de Jesús $(6,6 b)$

Misión de los Doce $(6,7-13)$.

b) Opiniones poco acertadas sobre Jesús $(6,14-16)$

Muerte de J. Bautista: prefigura la de Jesús $(6,17-29)$

"Sección de los panes:"

Primera multiplicación de los panes $(6,30-44)$

Jesús anda sobre el agua $(6,45-52)$

Sumario de curaciones $(6,53-56)$

Discusión sobre lo puro $(7,1-23)$

Curación de la sirofenicia $(7,24-30)$

Curación del sordomudo (7,31-37)

Segunda multiplicación de los panes $(8,1-9)$

Jesús atraviesa el mar y va a Dalmanuta $(8,10)$

Discusión sobra el signo del cielo $(8,11-13)$

c) Ceguera de los discípulos $(8,14-21)$

Transición: curación del ciego de Betsaida $(8,22-26)$

Segunda parte: el misterio del Hijo del hombre $(8,27-16,8)$

1) El "camino" del Hijo del hombre - seguir a Jesús $(8,27-10,52)$

La confesión de Pedro $(8,27-30)$

a) Primer anuncio de la pasión $(8,31)$

Incomprensión de los discipulos $(\mathbf{8 , 3 2 - 3 3 )}$

Instrucción sobre el seguimiento hacia la cruz $(8,34-9,1)$

Complementos catequéticos: transfiguración (9,2-13) exorcismo $(9,14-29)$

b) Segundo anuncio de la pasión (9,30-31)

Incomprensión de los discipulos $(9,32-34)$

Insirucción sobre el servir (9,35-37)

Complementos calequélicos: reglas para la comunidad $(9,38-50)$ instrucción sobre el matrimonio $(10,1-12)$ bendición de los niños $(10,13-16)$

el joven rico y las riquezas $(10,17-31)$

c) Tercer anuncio de la pasión (10,32-34)

Incomprensión de los discipulos (10,35-37)

Instrucción sobre el servir (10,38-47)

Transición: curación del ciego de Jericó $(10,46-52)$

2) Revelación en Jerusalén - ruptura definitiva con los judios $(11,1-13,37)$

a) Entrada mesiánica en Jerusalén $(11,1-11)$

b) Maldición de la higuera - purificación del templo $(11,12-25)$ 
c) Discusiones con los adversarios $(11,27-12,44)$ :

Primera serie: el poder de Cristo $(11,27-44)$

parábola de los viñadores $(12,1-12)$

Segunda serie: el tributo $(12,13-17)$

la resurrección $(12,18-27)$

el primer mandamiento $(12,28-34)$

Cristo, Señor de David (12,35-37)

Advertencia contra los escribas (12,38-40)

Apéndice: la of renda de la viuda (12,41-44)

d) Discurso escatológico (13,1-37)

Introducción $(13,1-4)$

Señales precursoras (13,5-23)

La venida del Hijo del hombre $(13,24-27)$

Parénesis $(13,28-37)$

3) Pasión y resurrección $(14,1-16,8)$

a) Conspiración contra Jesús y unción en Betania (14,1-11)

b) Ultima cena $(14,12-25)$

c) Getsemaní $(14,25-52)$

d) Pasión (13,53-15,47)

e) Anuncio de la resurrección $(16,1-8)$

Apéndice canónico añadido posteriormente por la comunidad:

Apariciones del resucitado (16,9-20)

\section{Grandeza y debilidad de la manifestación de Jesús}

¿Qué quiere indicarnos Marcos estructurando asi su obra? Una vez ha indicado al lector/oyente, en el prólogo teológico de su obra, que Jesús es el Hijo amado de Dios $(1,11)$ y lo ha preparado para descubrir en él al "Siervo de Yahvé," ${ }^{31}$ se propone, como meta de la primera parte de su obra $(1,14-8,22)$, desarrollar cómo el misterio de la persona de Jesús se va revelando progresivamente a los hombres. Las palabras y los hechos de Jesús, sobre todo en la medida en que son interpretados a la luz del Antiguo Testamento que era la Sagrada Escritura de sus oyentes, resultan tan impresionantes, que los hombres testigos de ellos se han de preguntar, al igual que los destinatarios del evangelio, a quienes representan: "¿Quién es éste, que hasta el viento y el mar le obedecen'" $(4,41),{ }^{32}$ que tiene poder sobre los demonios (cᄃ. 1,21-28; $5,1-20$ ), que cura a los paralíticos y perdona pecados (cf. 2,1-12), que limpia a los leprosos (cf. $1,40-45)$ y resucita a los muertos $(5,21-43)$, que multiplica los panes (cf. 6,34-44 y 8,1-9) y cura a los sordos $(7,31-37)$ y a los ciegos $(8,22-26)$ ? ¿Quién es éste que llama con poder a los hombres para que lo sigan (cf. 1,16$20 ; 2,14 ; 3,13-19)$ y los envía a predicar, dándoles poder para expulsar demonios y curar enfermos (cf. 6,7-13)? ¿Quién es éste que interpreta con tanta libertad y autoridad la palabra de Dios, la ley (cᄃ. 2,1-3,5 y 7,1-23)?

Pero este aspecto glorioso es sólo una cara de la moneda en la presentación de Jesús que nos of rece Marcos en la primera parte de su obra. La otra ca- 
ra no resulta menos sorprendente y es como un hilo conductor que atraviesa el texto. Llama la atención, en primer lugar, que Jesús no recibe nunca por parte de los hombres, durante toda esta parte del evangelio, el título de "mesías" o de "hijo de Dios." 33 En segundo lugar -y esto resulta aún más significativo dentro de la estructura del evangelio- Marcos tiene mucho interés en subrayar que la actuación de Jesús con poder no lleva automáticamente a creer en él. Todo lo contrario. Parece que cuánto más revela Jesús su poder, tanto más provoca la oposición - o, al menos, la incomprensión- de quienes lo rodean. En cfecto, el primer bloque narrativo de esta primera parte $(1,14-3,6)$ culmina en la ceguera y oposición de los adversarios de Jesús quienes quieren matarlo (cᄃ. 3,6). El segundo bloque $(3,7-6,6 a)$ termina con la ceguera de los habitantes de Nazarel, el pueblo donde Jesús se crió (cৎ. 6,1), quienes se escandalizan de él y no lo aceptan (6,1-6a). El tercer bloque, finalmente, concluye con la ceguera de los mismos discipulos de Jesús (cf. 8,14-21), un hecho tanto más sorprendente, cuanto que ellos han sido los iestigos privilegiados de las obras y de las palabras de Jesús. ${ }^{34}$ Este contraste entre la revelación creciente de Jesús y la incomprensión progresiva que provoca, Marcos lo utiliza para destacar dos cosas que le parecen fundamentales: a) que la actuación de Jesús con poder es algo ambiguo y que, por tanto, necesita ser interpretada dentro de las coordenadas históricas del personaje Jesús de Nazaret a fin de que pueda ser comprendida adecuadamente; b) que la sombra de la cruz se proyecta ya $-y$ de una manera constitutiva, como veremos luego- desde los inicios sobre la persona y la obra de Jesús.

En la segunda parte del evangelio, Marcos va a explicar dónde radica la dificultad para comprender la revelación de Jesús. Pero como es algo que resulta difícil de ver dentro de la lógica humana, que es la que quería denunciar en su comunidad, por ello sitúa aquí una pericopa que hace de puente entre la primera y la segunda parte: la curación del ciego de Betsaida (cf. 8,22-26). En la intención de Marcos se trata de una pericopa claramente de transición la cual forma inclusión con otra curación de un ciego, el de Jericó (cᄃ. 10,46-52). Pues después de haber constalado la ceguera total de los hombres - desde los enemigos de Jesús hasta sus discipulos- y antes de empezar a desarrollar con claridad aquel aspecto de la persona de Jesús que resulta francamente escandaloso - me refiero a la cruz-, la curación del ciego en Marcos tiene un significado claramente simbólico. ${ }^{35}$ quiere hacernos descubrir que si Dios no nos abre los ojos, si no transforma nuestra manera de ver las cosas, no somos capaces por nosotros mismos de entender el misterio de la cruz del Hijo del hombre y, mucho menos, de seguir a Jesús en el camino de la cruz que a partir de 8,31 dominará todo el evangelio.

\section{El escándalo de la cruz}

Con la confesión de Pedro en 8,27ss. y el primer anuncio de la pasión en 8,31, Marcos imprime un tono nuevo en su obra y nos da la clave de lectura que nos permite descubrir el núcleo de su pensamiento teológico y la respuesta a las preguntas que se nos planteaba en la primera parte del evangelio. 
También en esta segunda parte parece que Marcos ha distribuido el material del que disponia en tres bloques $(8,27-10,52 ; 11,1-13,37$ y $14,1-16,8)$ los cuales tienen como hilo conductor e idea central la pasión de Jesús la cual domina asi claramente -incluso desde el punto de vista literario- la mayor parte del segundo evangelio. ${ }^{36}$ Sobre todo el primer fragmento de esta segunda parte está muy trabajado redaccionalmente por Marcos - el análisis literario confirma aquí una vez más los resultados del análisis teológica ${ }^{37}-$ y nos da unas pautas de lectura muy claras que nos permiten descubrir la preocupación teológica primordial de Marcos al escribir su obra.

Marcos comienza aqui con una confesión de le: Pedro proclama que Jesús es el "Mesias"' (cf. 8,29). Es la primera vez en el evangeito de Marcos que un hombre da a Jesús este título, un titulo, por otro lado, muy importante para una comunidad que se sabia en continuidad con el A.T. Por eso es muy importante que nos fijemos en los rasgos concretos que enmarcan esta confesión en el relato de Marcos. En 8,27-30 leemos: "Salió Jesús con sus discipulos hacia los pueblos de Cesarea de Filipo, y por el camino hizo esta pregunta a sus discipulos: ‘Quién dicen los hombres que soy yo?' Ellos le dijeron: 'Unos, que Juan el Bautista; otros, que Elias; otros, que uno de los profetas.'El, entonces, les preguntó: 'Y ustedes, ¿quién dicen que soy yo?' Pedro le contestó: 'Tú eres el Mesías.' $Y$ les mandó enérgicamente que a nadie hablaran acerca de él."

Aparte de indicar que la pregunta sobre quién es Jesús está hecha "por el camino" - más adelante veremos que esto tiene su importancia en Marcos ${ }^{38}$ - , el redactor hace aqui una observación que es capital para poder entender la teología de Marcos. Me refiero al v. 30: “'les mandó enérgicamente que a nadie hablaron acerca de él." Esta prohibición resulta, francamente, sorprendente y no queda suficientemente explicada suponiendo que, así, Jesús quiere esconderse y evitar el conflicıo en Jerusalén. ${ }^{39}$ Pues Pedro, en representación de los discípulos, acaba de dar la respuesta a la pregunta que se plantea todo el evangelio de Marcos. Diciendo que Jesús es el Mesias, Pedro recoge una de las confesiones más típicas de las primeras comunidades cristianas (cf. $\mathrm{Rm} .1,3-4)$ ) que hemos encontrado ya en el título de la obra $(1,1) .{ }^{40}$ Es conveniente que notemos aquí que Jesús no niega que él sea el Mesías. Pero prohíbe severamente (!) a los discípulos que lo digan a nadie. ¿Por qué razón lo hace? La respuesta nos la da Marcos en el texto que pone a continuación, sobre todo si lo leemos a la luz de las indicaciones que nos of rece la estructura y contenido del primer bloque de material que encontramos en esta segunda parte (cf. 8,27$10,45)$.

\section{Los anuncios de la pasión}

Si en 8,27-29 indica Marcos quién era Jesús para la gente y los discipulos, ahora, a continuación, es Jesús mismo quien nos dice quién es él: “'Y comenzó a enseñarles que el Hijo del hombre debia sufrir mucho y ser reprobado por los ancianos, los sumos sacerdotes y los escribas, ser condenado a muerte y resucitar a los tres dias" $(8,31)$. Este contraste entre el título -en principio- glo- 
rioso de Mesias y el anuncio de la pasión, es algo que ha sido pretendido conscientemente por Marcos, como lo muestra el hecho de que en 8,32a -en contraste con 8,30- añade: "hablaba de esto abiertamente." De hecho aparece aqui un aspecto medular del pensamiento de Marcos, como nos lo muestra el que repita dos veces más este anuncio, dentro del fragmento que estamos considerando. Esta repetición, además, sucede siempre en el mismo lugar estratégico, como puede verse en la estructura (cf. 8,31;9,31; 10,32-34). Dado que dicha estructura es propia de Marcos, esta repetición no puede ser casual. Sólo con este hecho podemos sospechar ya que Marcos tiene un interés especial en estos anuncios de la pasión.

\section{La incomprension de los discipulos}

La importancia teológica de los anuncios de la pasión en Marcos viene confirmada por el hecho de que cada anuncio va seguido siempre de un episodio que pone de manifiesto hasta qué punto los discipulos de Jesús son totalmente incapaces de entender y de aceptar lo que Jesús acaba de revelar sobre sí mismo y sobre su destino. En efecto, cuando Jesús señala, por vez primera, que su destino estará en la linea del "justo que sufre," 41 se encuentra - según Marcoscon que el mismo Pedro, quien acaba de confesar la mesianidad de Jesús, no comprende ni acepta este rasgo esencial de la persona de Jesús y se opone abiertamente a ello: "Entonces, Pedro, tomándole aparte, se puso a reprenderlo" (8,32b). Hasta qué punto esto es peligroso y puede ser sintomático de la actitud de la comunidad, se ve en el hecho de que Jesús no amonesta a Pedro en privado, sino en público -Marcos piensa en los discípulos y en su comunidad - y en las palabras durisimas que Jesús dirige a Pedro: "Pero él, volviéndose y mirando a sus discípulos, reprendió a Pedro, diciéndole: ' QQuitate de mi vista, Satanás! porque tus pensamientos no son los de Dios, sino los de los hombres"' $(8,33) .^{42}$

Las perícopas que siguen a la segunda y tercera predicción de la pasión nos muestran que este contraste entre las palabras de Jesús y la reacción de Pedro como representante de los discipulos, no es casual ni fruto tan sólo de la tradición que recoge Marcos. Pues después del segundo anuncio (cr. 9,31), vuelve a subrayar que los discipulos "no entendian lo que les decia y tenian miedo de preguntarle" $(9,32)$ y nos ofrece un breve episodio en el cual se patentiza cómo los discipulos, en vez de querer seguir a Jesús en el camino que pasa por la humillación y la cruz, están preocupados por saber cuál de ellos será el más grande: "Llegaron a Cafarnaum, y una vez en casa, les preguntó: ‘De qué discutian por el camino?' Ellos callaron, pues por el camino habian discutido entre si quién era el mayor" (9,33-34). La misma reacción de incomprensión por parte de los discipulos volvemos a encontrarla en el episodio que sigue al tercer anuncio (cf. 10,33-34). Ahora son, en primer lugar, Santiago y Juan, los hijos del Zebedeo, quienes con su pretensión de sentarse a la derecha y a la izquierda de Jesús el dia en que sea glorificado (10,35-40), muestran hasta qué punto han comprendido mal el mensaje central de Jesús. Pero, en segundo lugar, también el resto de los discipulos muestra, con su 
reacción airada ante este hecho, que tampoco ellos están lejos de la actitud equivocada de los dos hermanos (cf. 10,41).

La regularidad con que Marcos hace quedar mal a los discípulos después de cada anuncio de la pásión, impone la pregunta: ¿qué interés podia tener en subrayar - precisamente en relación con la pasión- que los discipulos no entendian a Jesús? La respuesta la da el mismo Marcos a continuación de cada uno de los textos mencionados. Consiste en una instrucción que él pone en boca de Jesús. ${ }^{43}$ La repetición del motivo en sus variantes de seguimiento en el camino de la cruz o de servicio hasta dar la vida por los demás, indica hasta qué punto resuena aqui lo que constituye el núcleo de la teología de Marcos.

\section{El seguimiento en el camino de la cruz}

La primera pista que nos lleva a descubrir por qué, según Marcos, los discipulos no entendian a Jesús, cuando les anunciaba que moriría en la cruz, la encontramos en 8,34-36. ${ }^{44}$ Como indica el v. 34a, tenemos aquí una declaración de principios que es válida tanto para los Doce (representados por los discípulos) como para todos los cristianos (representados por la gente). Según Marcos, sólo quien está dispuesto a seguir a Jesús en el camino de la cruz, está en condiciones de poder comprender su mensaje: "Llamando a la gente a la vez que a sus discípulos, les dijo: 'Si alguno quiere venir en pos de mí, niéguese a si mismo, tome su cruz y sígame. Porque quien quiera salvar su vida, la perderá; pero quien pierda su vida por mi y por el evangelio, la salvará"' $(8,34-35)$. Este motivo del seguimiento de Jesús en el camino de la cruz - un camino que implica una manera determinada de vivir y no sólo una comprensión intelectual del mensaje de Jesús- es tan importante para Marcos, que a menudo sale en el fragmento que eslamos considerando.45 Parece que quiere subrayar la importancia que tiene para el cristiano el seguimiento activo de Jesús en el camino de la cruz.

Pero por si esto no habia quedado ya suficientemente claro al lector, Marcos vuelve a insistir en esta idea después de la segunda y tercera predicción/incomprensión. Para ello emplea el motivo del "servir." Así en 9,35, para contrarrestar los deseos de grandeza de sus discípulos, les dice: "Si uno quiere ser el primero, sea el último de todos y el servidor de todos" (cf. también 9,36). Este servicio conduce al cristianismo a dar su vida por los demás -es decir, el camino de la cruz-, a semejanza de lo que hizo Jesús, como nos indica claramente Marcos después del tercer anuncio/incomprensión: "Jesús, llamándolos (a los discípulos), les dice: saben que los que son tenidos como jefes de las naciones, las gobiernan como señores absolutos y los grandes las oprimen con su deber. Pero no ha de ser asi entre ustedes; sino que el que quiera llegar a ser grande entre ustedes, será su servidor, y el que quiera ser el primero entre ustedes, será esclavo de todos, que tampoco el Hijo del hombre ha venido a ser servido, sino a servir y a dar su vida como rescale por muchos" $(10,42-$ 45). ${ }^{46}$ Con estos principios, Jesús da un giro de 180 grados a los valores del mundo. 
¿Qué podemos deducir de la manera como Marcos ha estructurado este fragmento, tan elaborado por èl $(8,27-10,52)$, sobre la intención teológica del evangelista y el mensaje que quiere comunicar a su comunidad?

Una cosa aparece aqui muy claramente: que la revelación de Jesús es primaria y fundamentalmente la revelación de Aquel que fue libre y conscientemente a la cruz para dar su vida por los demás, por todos nosotros. Sólo a través de la cruz llegó a la resurrección. Una segunda cosa queda también muy clara y es fundamental para Marcos: que esta revelación de la cruz de Jesús comporta para el discipulo - Marcos crea que es la conditio sine qua non de la vida cristiana - la invilación a seguir personalmente a Jesús en el camino que lleva a la cruz.

\section{Crítica de una cristologia triunfalista}

Marcos, por tanto, nos presenta aqui una visión de Jesús que se contrapone totalmente a una visión criunfalista de su figura como la que encontramos, a menudo, en las esperanzas mesiánicas de la época de Jesús. Este podria ser el motivo principal -al menos en la concepción de Marcos por el cual Jesús prohíbe, en 8,30 , severamente a Pedro y al resto de los discípulos que digan a nadie que él es el Mesías. ${ }^{47}$ Dado que muchos judíos - y cristianos- veían en el "mesias" al triunfador que destruiría a los enemigos del pueblo, con gran poder, este título podia resultar equívoco y dar pie a una imagen equivocada de Jesús de Nazaret, una imagen triunfalista. Mientras la sombra de la cruz no se haya proyectado de manera clara y constitutiva sobre cualquier titulo que la comunidad pueda dar a Jesús, hay que poner sordina a cualquier título que se le dé. Según Marcos no basta con saber intelectualmente quién es Jesús - no basta una fe "ortodoxa," si se me permite esta fórmula que sería anacrónica en Marcos, sino que es esencial, para poder comprender quién es Jesús, la ortopraxis, es decir, el estar dispuesto a seguirlo en el camino, nada glorioso a los ojos del mundo, de la cruz. La incomprensión de los discípulos después de cada anuncio de la pasión quiere poner de manifiesto que si los discipulos no enlienden la disposición de Jesús a morir en la cruz, por fidelidad al proyecto de Dios, comprometido hasta lo último en el bien, en la vida del hombre, ello se debe al hecho de que tienen una visión excesivamente triunfalista de su persona -y de lo que debe ser la comunidad cristiana: una Iglesia triunfalista hubiera sido, evidentemente, un escándalo para Marcos; y si escribe su obra con estos rasgos es para evitar que los discípulos caigan en esta tentación tan peligrosa para la Iglesia- y no están dispuestos a seguirlo en el camino que lleva a la cruz.

Después de lo que acabamos de ver en este primer fragmento de la segunda parte del evangelio, podemos ahora comprender mejor por qué el evangelista, antes de que Jesús entre en Jerusalén (cf. 11,1 ss) y empiece el camino de la pasión, vuelva a poner una perícopa de transición que tiene un significado profundamente simbólico: la curación del ciego de Jericó (cf. 10,46-52). Teniendo en cuenta que Marcos ha colocado prácticamente todos los milagros de Jesús en la primera parte de su obra, nos hemos de preguntar por qué ha situado pre- 
cisamente en este lugar dicho milagro. 48 Los especialistas creen, con razón, que ve en esta perícopa un sentido profundo. Pues Marcos, una vez ha revelado con claridad cuál es la esencia de la persona de Jesús -el que morirá en la cruz y el que nos invita a seguirle en este camino-, se da cuenta de que esto es tan duro para el hombre que si Dios no nos abre los ojos de la fe, no seremos capaces de comprender el misterio de la cruz que se nos revelará, cada vez con más fuerza, a partir de 11,1 . No es casual, ahora, que en esta curación del ciego - a diferencia de la primera (if. 8,22-26) la cual forma inclusión con ésta, enmarcando literaria y teológicamente el fragmento que acabamos de considerar-, Marcos haya añadido, redaccionalmente, al linal del mismo, una palabra clave: "y lo seguía en el camino" $(10,52)$. Pues los hombres no sólo necesitan que Jesús les abra los ojos para poderlo entender cuando se revela como cl crucificado, sino que, además, necesitamos, cuando empieza ya la pasión, que nos los abra de tal manera que estemos dispuestos a seguirlo "en el camino" de la cruz.

Notemos, finalmente, a propósito de la estructura de esta segunda parte del evangelio, que Marcos, una vez ha narrado las controversias y ruptura definitiva de Jesús con los judios en Jerusalén (cf. 11,12-12,44) y ha puesio de relieve el significado escatológico (cf. cap. 13) y las persecuciones que tendrán que sufrir los cristianos por ser seguidores de Jesús (cf. 13, 9-13), es el evangelista que destaca mejor en su relaio los rasgos duros y escandalosos con los cuales, en la ıradición premarcana, se contaba la pasión y muerte de Jesús a la luz de la tradición veterolestamentaria del justo que sufre y del siervo de Yahvé. ${ }^{49} \mathrm{Al}$ mismo tiempo conviene nolar también, que originariamente, el relato de Marcos no terminaba con la narración de las apariciones pascuales, sino con el anuncio angélico de la resurrección (cr. 16,6) y el encargo, dado a las mujeres, de decir a los discípulos que fueran a Galilea, donde verian al Señor (cf. 16,7). Este aspecto, que es de capital importancia para poder comprender la intención teológica original de Marcos, lo desarrollaré en la segunda parte del articulo.

\section{Conclusión de la primera parte}

Hemos podido comprobar cómo la estruciura de Marcos, la cual tiene como eje el inisterio de la cruz, nos da una paula de lectura fundamental para poder comprender cómo quiere que leanos las tradiciones cristianas que él ha recogido en su obra. Sin negar, ni mucho menos, que Jesús actuó con poder. Marcos quiere que, ante todo, tengamos presente que Jesús es, por esencia, el crucificado que nos invita a seguirlo en el camino que él inició.

En orden a poder confirmar lo que acabamos de descubrir a propósito de la estructura, analizaré, en la segunda parte del articulo, algunos reloques redaccionales significativos que realizó en las tradiciones que recibió, concretamente en los que se referían a los milagros y a los seguidores de Jesús. Con ello espero poder confirmar mi tesis de que Marcos quiso corregir una espiritualidad triunfalista que ponia en peligro la fe de su comunidad. 


\section{Segunda parte: el "secreto mesiánico" y el fracaso de los seguidores de Jesús}

Jesús

\section{Introducción}

Para poder descubrir los retoques redaccionales que Marcos realizó en sus tradiciones, los especialistas han estudiado cuáles son las palabras y los motivos teológicos que se repiten continuamente. ${ }^{50}$ El análisis ha resultado muy fecundo, sobre todo a propósito de las tradiciones de milagros/exorcismos y de los discipulos (y familia) de Jesús, pues nos han permitido descubrir hasta qué punto el autor quiere corregir una espiritualidad, de tono triunfalista, que ponia en peligro la fe cristiana de su comunidad.

\section{Los milagros y exorcismos en Marcos}

Durante mucho liempo el evangelio de Marcos fue considerado como "el evangelio de los milagros," pues éstos ocupan en él un lugar proporcionalmente más amplio que en los otros evangelios. ${ }^{51}$ ¿Por qué dio Marcos tanta imporrancia a los inilagros de Jesús? ¿Qué pretendió relalándolos?

En las narraciones de milagros el interés principal de Marcos no es, evideniemente, el biográfico - ya en las tradiciones que recibió no era ésta la perspectiva que dominaba la narración-, aunque la abundancia de detalles "secundarios" en el relato haya dado pie a pensar, equivocadamente, que era asi. De hecho, hace algunos años determinadas interpretaciones apologéticas, hoy superadas, consideraban las narraciones como una descripción de los milagros hecha por un testigo ocular quien había conservado en su recuerdo aquellos pequeños detalles que, a menudo, se encuentran sólo en Marcos..$^{52}$ Pero el análisis de los textos no nos permite esta interpretación historicista, pues los milagros/exorcismos de Marcos están narrados siguiendo un esquema literario, típico y tradicional, el cual se encuentra también en los relatos de milagros de los taumalurgos helenisias y judios de aquel tiempo. La estructura de dichos relatos de milagro consta de cinco elementos fundamentales:

En primer lugar, presentación del enfermo (cf. 1,23; 5,2.25); a menudo se indican las circunstancias que subrayan el significado del milagro, como pueden ser la gravedad de la enfermedad ( $c$. $5,3 \mathrm{ss} ; 9,17 \mathrm{ss}$ ) o su larga duración (cr. $5,25 \mathrm{~s} ; 9,21$ ).

E.l segundo elemento es la pelición de curación (cr. 1,30.40; 5,22s.32; 7,$32 ; 9,17 s ; 10,475$ ).

El tercero es la curación del enfermo, por contacto o manipulación del taumaturgo (cf. $1,31.41 ; 5,28-30.41 ; 7,33 \mathrm{~s} ; 8,23.25 ; 9,27$ ) o/y por el poder de su palabra (cf. $1,25.41 ; 2,11 ; 3,5 ; 4,29 ; 5,8.34 .41 ; 7,29.34 ; 9,25: 10.52$ ).

El cuario elemento es la demosiración de la curación (cf. $1,31,44 ; 2,11$ $12 \mathrm{a} ; 5,15.43 ; 7,35 \mathrm{~b} ; 8,25 \mathrm{~b}$ ).

Y finalmente, el efecto que el milagro produce en los presentes: motivo de la admiración o del temor religioso (cf. $1,27 \mathrm{~s} ; 2,12 \mathrm{~b} ; 4,41 ; 5,20.42: 6,51 ; 7,37)$. 
A menudo esta reacción de quienes han sido testigos del milagro es presentada como un coro final.

Podemos concluir, por tanto, que el interés de Marcos -y de la tradición premarcana- al narrar los milagros no era primariamente históricobiográfica, ${ }^{53}$ sino cristológico. Pues los milagros son, fundamentalmente, testimonios de fe al servicio de la misión.

\section{Los milagros al servicio de la misión}

Resulta importante constatar que los milagros de la tradición cristiana que Marcos ha recogido, están explicados de tal modo que los lectores/oyentes del milagro tengan que preguntarse: “¿quién es este personaje que es capaz de realizar tales obras?" Y la manera cómo se relata el milagro - sobre todo si se tienen en cuenta las alusiones explicitas o implícitas al A.T.-, permite que los oyentes encuentren la respuesta adecuada a dicha pregunta. Pucs caen en la cuenta de que Jesús es más grande que Jonás (cโ. 4,35-41 con Jonás 1), más grande que Moisés, Elías u otro de los profetas de Israel. Más aún, el hecho de que tenga poder incluso sobre el mar, que cure a un paralítico como signo de que tiene poder de perdonar pecados o que resucite a un muerto, hace pensar que Jesús tiene el poder de Dios. ${ }^{54} \mathrm{Al}$ mismo tiempo se subraya la importancia de la fe en todos estos milagros (cf. 2,$5 ; 4,40 ; 5,34.36 ; 9,23$ ), de modo que en 6,1-6 llegue a afirmar que Jesús casi no pudo hacer milagros en su ciudad, Nazaret, porque no encontró fe alli. Por este motivo, sin duda, los elementos mágicos o manipulaciones por parte del taumaturgo apenas se encuentran en los inilagros de Marcos. ${ }^{55}$ Más bien predominan los realizados por la palabra poderosa de Jesús. Ello se debe a que la misión cristiana tiene más interés en la relación personal que se crea entre el taumaturgo y el enfermo que no en el aspecto extraordinario, misterioso, del milagro.

En este contexto y supuesto que los milagros y colecciones de milagros :visian ya antes de que Marcos escribiera su obra -y su comunidad los . 1) nocería sin duda-, debemos preguntarnos cuál era la concepción teológica : i configuraba estos relalos premarcanos, si queremos descubrir cuáles ficicon los reioques redaccionales que realizó en ellos.

iesiis como canmanurgo divino

En la Iradición prenarcana, los milagros eran, ante todo, una epifanía de a divinidad de Jesiss, es decir, eran una manifestación del poder de Jesús (cf. $5,30)$.56 Duranle bastante (iempo fue una opinión bastante corriente entre los ispecialisıas, que la comunidad premarcana veia en Jesús como el theios aner - cl taumalurgo divino de las religiones paganas, sobre todo helenistas, de silvacion $n^{57}$ - y que esta figura habia ayudado a la comunidad cristiana a :omprender mejor la persona de su Maestro. De hecho, el judaismo helenista precristiano habia ya descubierto la posibilidad de equiparar a sus grandes personajes - Elias, Eliseo, Moisés- con estos "hombres divinos." 58 En este senlido, la comunidad cristiana que confesaba a Jesús con los rasgos del profeta 
escatológico que habia venido a vencer el poder del demonio (cf. 1,21-28), no habria encontrado ninguna dificultad en aprovechar el motivo del "hombre divino" para intepretar el significado de Jesús. Esta interpretación, con todo, no es aceptada hoy por todos los especialistas. 59

Sea lo que sea de la relación entre la figura del "hombre divino" y la presentación cristiana de Jesús a través de sus milagros, en todo caso queda suficientemente claro que la tradición cristiana de los milagros de Jesús antes de Marcos, se interesaba de modo particular por la figura de Jesús como taumaturgo divino que tenía poder sobre los demonios (cf. $1,21-28 ; 5,1-20$ ), ега Señor de los elementos naturales (cf. 4,35-41; 6,45-51), curaba a los enfermos $(1,29-31.40-45 ; 2,1-12 ; 3,1-5 ; 5,25-34 ; 7,32-37 ; 8,22-26 ; 10,46-52)$, resucitaba a los muertos (cf. 5,35-43), multiplicaba los panes (cᄃ. 6,34-44; 8,1-10). En esta tradición, por tanto, Jesús sobresalia por su poder.

Pero este rasgo que, en principio, revelaba un aspecto profundo de la persona de Jesús, daba pie, al mismo tiempo, a que se pudiera considerar su figura de modo unilateral. Un primer peligro, por ejemplo, aparece en -y queda corregido por- el relato de la curación de la mujer que padecía pérdidas de sangre (cf. 5,25-34). Me refiero a una concepción mánica o mágica del poder de Jesús según la cual basta con tocar al taumaturgo para que se transmita automáticamente su poder sanador (cf. $5,28 \mathrm{~s}$ ). La pregunta de Jesús "¿quién me ha tocado?" se propone, como meta, que la mujer se arrodille delante de Jesús y confiese lo que ha hecho ( $c[.5,30-33$ ), a fin de que ponga de manifiesto que -como le indica Jesús- es su fe la que la ha salvado (cf. 5,34). Pero hay también un segundo peligro, más serio, que no resulta tan fácil de contrarrestar. Me refiero al hecho de que los milagros puedan fomentar una concepción tan gloriosa de la cristología que oscurezca el significado central que tiene la cruz para la fe cristiana. De hecho, este peligro lo había encontrado ya -y criticado (cf. 1 Co. 1,17ss) - Pablo en la comunidad de Corinto. ¿Cómo intentó corregir Marcos esta peligrosa desviación en la interpretación de la figura de Jesús?

\section{La aportación teológica de Marcos}

La primera - y la más fundamental - aportación del evangelista consistió en haber situado los relatos de milagro dentro de un marco que favoreciera una comprensión auténtica y profunda de su significado (me refiero al marco de su "evangelio") y que contrarrestara las concepciones triunfalistas de la cristología de la comunidad, al situar los milagros de Jesús dentro de las coordenadas de la "vida" real de Jesús, una vida que lo condujo a la cruz. ${ }^{60}$

Pero Marcos está tan preocupado por el hecho de que la comunidad pueda entender mal los milagros de Jesús, que no se conforma con colocar los milagros dentro del macrocontexto del evangelio, por importante que sea el contexto para una intepretación adecuada de un texto concreto. Quiere, adeinás, que la sombra de la cruz se proyecte sobre los mismos textos. La tarea que se propone no parece en principio nada fácil, pues las tradiciones que Marcos había recibido eran unas tradiciones muy venerables - de alguna manera 
procedian de Jesús de Nazaret a través de los primeros testigos cristianos-, que él, como teólogo tradicional que era, ${ }^{61}$ quería conservar fielmente. Por eso procura respetar al máximo las tradiciones recibidas. Pero añade también, de modo bastante sistemático, un elemento que recuerde al oyente o lector la perspectiva cristiana con la cual ha de ver siempre la actividad taumatúrgica de Jesús. Me refiero a las "órdenes de silencio" que reciben quienes son curados o son testigos de una manifestación gloriosa de Jesús.

\section{El "secreso mesiánico"}

Leyendo el evangelio de Marcos sorprende, de hecho, que en las tradiciones de exorcismos y milagros que el evangelista recoge, se encuentren continuamente - a menudo en textos considerados como redaccionales por los especialistas ${ }^{62}$ - unas "órdenes de silencio," dadas por Jesús, las cuales prohiben publicar lo que acaba de acontecer o se revelen los títulos gloriosos de Jesús (cf. 1,$25 ; 1,34 ; 3,11 ; 1,44 ; 5,43 ; 7,36 ;$ cf. también 8,26). Al mismo tiempo se ve, por el contexto, que estas órdenes de silencio no pueden ser cumplidas (cf. 5,43 con $5,38 \mathrm{~s}$ ) y son, de hecho, desobedecidas (cf. 1,44s; 7,36: "Jesús les mandó que a nadie se lo contaran. Pero cuanto más se lo prohibia, tanto más ellos lo publicaban"). Y en otros textos parece que Jesús, después de haber realizado algún milagro, quiera esconderse (cf. 1,$35 ; 6,46 ; 8,9 ; 9,30$ ), sin conseguirlo (cf, 7,24).

Constatamos, por tanto, que tanto en las tradiciones -en principio independientes - de milagros, como en las de exorcismos y en los sumarios redaccionales, ${ }^{63}$ encontramos el motivo de las "órdenes de silencio." Este motivo, además, lo encontramos también en otros relatos que corresponden a otro tipo de tradiciones: por ejemplo en 8,30, inmediatamente después que Pedro ha confesado que Jesús es el "mesías" o en 9,9 , después que los discípulos han sido testigos de la transfiguración de Jesús.

Podemos concluir, por tanto, que este motivo teológico sale tan a menudo en Marcos y en relatos de tradiciones tan distintas, que nos revela un motivo importante de la redacción. ${ }^{64}$ La insistencia en el motivo nos indica, a la vez, hasta qué punto debe encontrarse aquí una idea teológica que interesaba mucho a Marcos. Por eso debemos preguntarnos qué es lo que el autor quiere que su comunidad descubra en el texto.

Por un lado, parece que los distintos relatos de Marcos se proponen como meta manifestar quién es Jesús, revelar su poder. Pero, por otro, parece también que esta revelación tenga que quedar "secreta." Por eso M. Dibelius llamó a Marcos "el evangelio de las epifanias secretas." Una primera explicación del motivo del silencio nos la da el mismo Marcos. Efectivamente, en 9,9 nos indica la razón de la orden de silencio y el tiempo que debe durar. Se refiere aquí a la transfiguración de la cual acaban de ser testigos los tres privilegiados: "cuando bajaban del monte les ordenó que a nadie contasen lo que habían visto hasta que el Hijo del hombre resucitara de entre los muertos." Según este texto no parece que Marcos, en principio, se oponga a una manifestación de la gloria de Jesús, sino que piensa, tan sólo, que ésta no puede ser considerada de 
un modo aislado: debe ser vista a la luz de la muerte y de la resurrección, que son el marco dentro del cual deben ser situados los milagros y los títulos mesiánicos de Jesús. Sólo dentro de la perspectiva del Jesús crucificado puede decirse, con propiedad, que Jesús es el taumaturgo divino o el Mesías. Parece, por tanto, que las órdenes de silencio tienen sólo una duración limitada: el "secreto mesiánico" llega sólo hasta el momento de la muerte y de la resurrección de Jesús.

Pcro, ies ćsı la úlima palabra de Marcos sobre el tema? De hecho ellcontramos un texio, precisamente al'final de la obra original de Marcos (cf. 16,7-8), que nos obligará a superar esta primera respuesta que hemos dado al problema planteado por el denominado "secreto mesiánico," pues descubriremos en él que el "secreto" sigue teniendo validez incluso después de pascua.

\section{El encuentro con el resucitado en Galilea}

Después de lo que acabamos de ver y a la luz de lo que encontramos en los otros evangelios, sorprende, en principio, que la versión original de Marcos concluyera en 16,8, sin narraciones de las apariciones pascuales y de un modo que parece abrupto. Este hecho sorprendió ya a las primeras comunidades cristianas las cuales muy pronto se apresuraron a "completar" este evangelio con ayuda de las tradiciones pascuales que encontraron en los otros evangelios. ${ }^{65}$

El final original de Marcos resulta, ciertamente, enigmático, pues en 16,7-8 leemos inmediatamente después que el "ángel intérprete" haya proclamado a las mujeres el mensaje pascual que interpreta el significado de la tumba que han encontrado abierta y vacia (cf. 16,4-6): "Pero vayan a decir a sus discípulos y a Pedro que irá delante de ustedes; allí lo verán, como les dijo. Ellas salieron huyendo del sepulcro, pues un gran temblor y espanto se habia apoderado de ellas, y no dijeron nada a nadie porque tenian miedo."

La mayoría de los especialistas atribuyen a la labor redaccional del evangelista, tanto aquí en 16,7 como en $14,28,66$ la orden dada a los discipulos de ir a Galilea al encuentro del resucitado. No es casual que en Marcos el encuentro con el resucitado sea situado precisamente en Galilea. Pues Galilea tiene, de hecho, un significado peculiar en Marcos el cual contrasta con la manera como el evangelista habla de Jerusalen. ${ }^{67}$ Mientras Jerusalén es vista negativamente como el lugar desde el cual vienen los enemigos de Jesús (cf. 3,$22 ; 7,1$ ) y en el cual sufrió y murió (cᄃ. 10,33; 14-15), Galilea, en cambio, es contemplada de manera muy positiva: es el lugar donde se inició la actividad pública de Jesús (cf. 1,14), donde realizó la mayor parte de su revelación con poder (cf. 1,20-8,21); en Galilea escogió Jesús a sus discípulos (cf. 1,16-20; 2,14: 3,13-19), los envio a predicar (cf. 6,6b-13) y los preparó para la crisis de la pasión (cf. 9,30ss.); desde Galilea empezó la misión cristiana a los paganos (cf. $5,1-20 ; 7,24-30)$. Por todo ello y dada la importancia que tiene la vida de Jesús en Galilea (la muerte de Jesús en la cruz es la consecuencia de su actividad alli; cf. $3,6.22-30 ; 7,1-16 ; 8,11 ; 8,31 ; 9,31 ; 10,32-34)$, creo que con este texto Marcos quiere subrayar que es en Galilea donde los discípulos volverán a encontrar a 
Jesús, ahora resucitado. Para Marcos, Galilea, más que un lugar geográfico, es un lugar teológico: es un lugar que esıá caracıerizado por el estilo de vida de Jesús de Nazarel y donde la comunidad de Marcos a semejanza de los primeros discípulos, puede hacer ahora una experiencia cualificada del resucitado. Ahora para poder encontrar al resucitado - y ésı es una de las cosas que Marcos quiere subrayar al final de su obra- ya no hay que ir a Jerusalén, a su templo, a su culıo y a sus leyes de pureza (cf. $11,12-25 ; 14,58$ y $7,1-23$ ), ni a la tumba que se encuentra vacia. La revelación de Dios resucitando a Jesús no apunta ahora a un pasado cstático, rosilizado y manipulable por el creyente, sino que esıá Ilena de dinaınismo, un dinamismo marcado radicalmente por la vida de Jesús de Nazareı. ${ }^{68}$ Hay que ponerse en camino hacia Galilea al encuentro del Hijo del hombre que vendrá en la parusia ("entonces verán venir al Hijo del hombre" 13,26a) para la cual hay que esiar preparado (cf. 13,28-36). En este sentido, ningún evangelio da tanta importancia a la parusía como Marcos, pues en los demás los relatos de las apariciones pascuales anticipan ya, en cierto modo, la segunda venida de Jesús que él habia anunciado antes de morir. En Marcos, en cambio, no se narra ninguna aparición del resucitado. El evangelio concluye con el encargo dado a los discípulos $-y$ en ellos a la comunidad- de ponerse en camino. Sólo así encontrarán al resucitado, aunque no saben cuándo ni cómo se les manifestará exactamente. ¿De qué camino se trata pues?

\section{El camino del resucilado}

Para Marcos no todos los caminos llevan a Jesús. No se trata, por ejemplo, de un camino fácil y glorioso. Por eso, por si la comunidad no habia acabado de entenderlo a lo largo de la lectura del evangelio, acaba su obra de una manera tan sorprendente y, a primera vista, ininteligible. Pues en $16,8 b$ -y la mayoria de los especialistas piensan hoy que este texto es redacciona $1^{69}$ - concluya diciendo que las mujeres no cumplieron la orden que les había dado el ángel, sino que "no dijeron nada a nadie porque tenian miedo." ¿Por qué concluye Marcos con estas palabras?

Evidentemente no quiere presentar, sin más, a estas mujeres como un modelo de desobediencia a la revelación divina. 70 Tampoco quiere que la comunidad se haga la pregunta historicista de cómo se han podido enterar del acontecimiento, si ellas no dijeron nada a nadie. ¿Qué pretende, pues, con este final?

Lo que hemos observado antes a propósito del "secreto mesiánico" nos puede ayudar a encontrar la respuesta adecuada. Pues aquí volvemos a encontrar el motivo del silencio y un procedimiento literario semejante al que encontrábamos en las "órdenes de silencio." Sólo que aquí sucede lo contrario de lo que acontecia alli. En los milagros veíamos cómo Jesús, a menudo, mandaba que no lo dijeran...y ellos lo decian. Aqul las mujeres reciben la orden de decirlo... y callan. ¿Por qué?

Creo que al leer este final, la comunidad tendría que pensar -y esto es precisamente lo que pretende Marcos en las órdenes de silencio que acompafiaban los milagros y manifestaciones gloriosas de Jesús. En un principio, la co- 
munidad podria haber pensado, a la luz de 9,9, que el "secreto mesiánico" sólo tenía validez para la vida pública de Jesús, antes de su muerte y resurrección. Pero Marcos no lo ve así. Si después de la resurrección y como conclusión redaccional de su obra, nos vuelve a recordar el motivo del "secreto mesiánico" y de la incomprensión de la obra de Jesús por parte de sus seguidores, ello se debe a que quiere sacudir la seguridad y autoconfianza excesiva de los miembros de su comunidad. Quiere que caigan en la cuenta de la complejidad y dificultad que comporta, por sí misma, la revelación cristiana cuya comprensión adecuada no queda garantizada sólo por el hecho de haber sido testigos de las obras gloriosas de Jesús o de haber recibido el mensaje divino de la resurrección. En este sentido podemos decir, que el silencio de las mujeres sirve a Marcos para dejar bien patente lo que ha sido la intuición teológica nuclear de coda su obra y que descubrimos ya a propósito de la estructura que dio a su obra: que la cruz del resucitado es el catalizador de todo pensamiento cristiano y que su sombra puede planear sobre todo seguimiento de Jesús, que debe ser, por esencia, también después de pascua, un seguimiento en el camino de la cruz (cf. 8,34ss.). Si Marcos insiste tanto en este aspecto es porque debía estar preocupado por el hecho de que sus cristianos olvidaran que el "secreto mesiánico" pertenece a la estructura teológica de todo pensamiento cristiano y pudieran entender mal a Jesús por no estar dispuestos a seguirle en el camino de la cruz. No es el camino de una Iglesia triunfalista el que conduce a Jesús. ¡Sólo el camino de la cruz es el camino cristiano!

Desde esta perspectiva se puede comprender que, si la comunidad tendia - como parece que podemos deducir de los acentos que Marcos dio a su obra- a fijarse demasiado en los aspectos gloriosos de Jesús en detrimento de los aspectos que lo llevaron al conflicto con las autoridades políticas y religiosas y a la cruz, ${ }^{71}$ no tuviera, entonces, Marcos especial interés en concluir su evangelio con un relato detallado de las apariciones del resucitado que hubieran podido fomentar aún más las tendencias triunfalistas de sus cristianos.

Todo eso queda aún más claro si analizamos el papel que Marcos hace desempeñar a la familia y a los discípulos de Jesús, así como a las mujeres que siguieron a Jesús desde Galilea (cf. 15,40s).

\section{El fracaso de los seguidores de Jesús}

Los textos que hablan de la familia, de los discipulos y de las mujeres que seguian a Jesús, llevan claramente la impronta de la teologia del redactor. En efecto, una comparación sinóptica de la manera cómo los evangelistas tratan la figura de estos personajes venerables, muchos de los cuales fueron las columnas de la fe de la comunidad (cf. Ga 2,9), revela, por un lado, hasta qué punto Marcos subraya, de manera sorprendente y consecuente, la incomprensión de la persona de Jesús por parte de todos ellos, mientras que, por otro lado, los demás evangelistas y, sobre todo Lucas, se esfuerzan por suavizar o corregir -en la medida en que ello era compatible con la fidelidad histórica, tal como se entendia en la época - los textos en los que todos ellos quedaban tan mal en Marcos. 


\section{La incomprensión de la familia}

Los primeros amigos de Jesús que quedan mal en Marcos por no poder entenderlo son los de su propia familia. Los textos en cuestión se encuentran en 3,21 y 3,31-34. Marcos, quien recoge aqui, sin duda, tradiciones de la comunidad, sitúa estos textos en un contexto tan negativo - sobre todo si se tiene en cuenta que sirven de marco a una pericopa que nos ofrece las interpretaciones malintencionadas de la figura de Jesús por parte de sus adversarios por excelencia (cf. 3,22-30) ${ }^{72}$-, que Lucas se siente obligado a omitir el primero de ellos y a modificar tanto el segundo como el contexto general, pues piensa que dan una imagen demasiado negativa de la lamilia de Jesús. ${ }^{73}$

Lo primero que nos dice Marcos a propósito de la familia de Jesús es que ésta creia que Jesús se habia vuelıo loco: "Se enteraron sus parientes y fueron a hacerse cargo de él, pues decian: 'Está fuera de si'"' $(3,21)$. Y si a continuación añade que los maestros de la ley quienes habían venido de Jerusalén, afirmaban que Jesús estaba endemoniado (cf. 3,22ss), es que el evangelista tenia interés por mostrar que la familia de Jesús tenia un nivel de comprensión de la persona del Maestro parecido al que tenían los enemigos de Jesús. Por eso resulta también "escandaloso" en este contexto lo que Marcos añade, a continuación, a propósito de la familia de Jesús: "Llegan su madre y sus hermanos, y quedándose fuera, lo envian a llamar. Estaba mucha gente sentada a su alrededor. Le dicen: ' $O$ Oye!, tu madre, tus hermanos y hermanas están fuera y te buscan.' El les responde: '¿Quién es mi madre y mis hermanos?' Y mirando en torno a los que estaban sentados en corro, a su alrededor, dice: 'Estos son mi madre y mis hermanos. Quien cumpla la voluntad de Dios, ése es mi hermano, mi hermana y mi madre"'(3,31-35). En el contexto que acabo de mencionar, parece que la contraposición entre quienes estaban sentados alrededor de Jesús y su familia, no sólo implica que ésta no entendia a Jesús (cf. 3,21 ), sino que, además, tampoco cumplía la voluntad de Dios. ${ }^{74}$

¿Por qué presenta Marcos críticamente a la madre y a los hermanos de Jesús, unos personajes que, como sabemos por otros textos del N.T., eran vistos muy positivamente por las primeras comunidades cristianas? ${ }^{75}$

Creo que la respuesta no se encuentra, como han propuesto algunos, en la antipatía de Marcos contra la comunidad de Jerusalén, ${ }^{76}$ donde, sin duda, Santiago y los otros hermanos de Jesús ocuparon un lugar relevante después de la resurrección (cf. Hch. 15 y Ga.2), sino a su deseo de llamar la atención de su comunidad, con la ayuda del ejemplo "negativo" de unos personajes tan venerables como la madre y los hermanos de Jesús, sobre el peligro real que la amenaza, si no está dispuesta a aceptar a Jesús de Nazaret, tal como se manifestó en realidad durante su vida pública, y si no quiere seguirlo en el camino que lo llevó a la cruz.

\section{La incomprension de los discípulos}

Es sobre todo durante el relato de la pasión de Jesús cuando aparece más clara la contraposición de su figura (y el modo como va hacia la cruz) y la figu- 
ra de los discípulos (y el modo como éstos procuran huir de ella). Marcos subraya aqui - siguiendo, en parte, lo que ya encontró en sus fuentes- el fracaso de los discipulos. Pues es un discipulo, Judas Iscariote, uno de los Doce, quien traiciona a Jesús ( $c \digamma$. 14,10; lambién 14,20s; 3,19). Y en el momento del prendimiento de Jesús (cf. 14,43-52), lodos lo dejarán solo y huirán (cf. 14,50; también 14,51s.), de manera que al pie de la cruz sólo se encontrarán, según Marcos, unas mujeres quienes habian seguido a Jesús desde Galilea (cf. 15,40 s). Incluso Pedro, el portavoz de los discipulos, quien habia proclamado que estaba dispuesto a morir con Jesús (cf. 14,29-31), lo negará tres veces -la última con maldiciones y juramentos-, mientras Jesús es condenado a muerte por el sanedrin y tiene que soportar las burlas de sus enemigos (cr. 14,66-72 con $14,55-65){ }^{77}$

El triste papel que Pedro y los Doce desempeñan en la pasión no sorprende a los lectores de Marcos, pues ya en Betania, en casa de Simón el leproso, el evangelista los ha presentado ${ }^{78}$ como no entendiendo lo que ha hecho la mujer que derramó el perfume sobre la cabeza de Jesús, lo cual les ha acarreado un reproche por parte del Maestro (cf. 14,3-9). Lo mismo ha ocurrido en Getsemaní, mientras Jesús ora y se prepara para la pasión (cf. 14,33s): Pedro, Santiago y Juan, representantes conspicuos de los Doce, duermen (cf. 14,37.40.41), de modo que Jesús tiene que decir a Pedro: "Simón, iduermes?, ¿ni una hora has podido velar? Velen y oren, para que no caigan en tentación; que el espíritu está pronto, pero la carne es débil" (14,37b.38). Este fracaso de los discípulos - lo vimos ya al hablar de la estructura- aparece desde el momento cuando Jesús empieza a hablar abiertamente de la pasión (cf. 8,32s.).

Este motivo de la incomprensión de los discípulos le parece tan importante a Marcos, que lo pone también a otros textos de su evangelio. Un texto muy interesante lo encontramos en el milagro de la tempestad calmada (cf́. 4,35-41), pues en un texto redaccional -rompe la estructura tipica de los relalos de milagro ${ }^{79}$ - Jesús hace el siguiente reproche a sus discípulos quienes acaban de ser testigos del milagro: “¿Por qué están con tanto miedo? ¿Todavia no tienen fe?" $(4,40) .80$ Son los discípulos quiénes no entienden el sentido de las parábolas (cf. 4,13; también 4,$10 ; 7,18$ ), a pesar de que Jesús se los explica todo ( $c$ [. $4,11 \mathrm{~s}$.14ss.34). Son los discípulos quiénes dan respuestas absurdas a las preguntas de Jesús (cf. 5,$31 ; 6,37 ; 8,4$ ) y lo confunden con un fantasma (cᄃ. 6,49). Son los discipulos - iy con esto termina la primera parte del evangelio de Marcos! - quienes no han comprendido las multiplicaciones de los panes y quienes reciben por ello el mismo reproche que, a propósito de las parábolas, habia dirigido Jesús a quienes no pertenecen a la comunidad (cf. 8,17-21 con 4,11-12). Son los discipulos quienes no son capaces de expulsar a determinados demonios (cf. 9,18b.28-29) y quienes no dejan que los niños se acerquen a Jesús (cᄃ. 10,13-14). En este contexto no nos sorprende ya que Pedro, como representante de los Doce, haga propuestas absurdas en el momento de la transfiguración de Jesús, pues "no sabia lo que decía" $(9,6 a)$. Como tampoco resulta raro que cuando Jesús dice que "es más fácil que un camello pase por el ojo de una aguja, que el que un rico entre en el reino de 
Dios" $(10,25)$, los discípulos pregunten asustados: "Pues, ¿quién se podrá salvar?" $(10,26 \mathrm{~b})$.

Después del repaso de todos estos textos, los cuales salen tan a menudo y en tradiciones tan distintas durante todo el evangelio de Marcos, creo que podemos concluir que la incomprensión de los discipulos es un motivo fundamentalmente redaccional ${ }^{81}$ el cual representa un interés particular del evangelista. ¿Cuál es, pues, dicho interés? ¿Qué queria mostrarnos Marcos con esıe motivo?

Una explicación posible - y es la que han intentado algunos autores ${ }^{82}$ seria el que Marcos hubiera escrito su obra para oponerse a la institución eclesial, representada aquí por los discipulos. Si Marcos hubiera respirado un espiritu antiinstitucional, se comprendería, entonces, perfectamente su interés en hacer quedar mal a los discipulos, quienes serian los representantes de la jerarquia eclesial.

Pero, personalmente, no me parece acertada esta explicación de los textos, pues en diversos lugares Marcos habla muy positivamente de los discípulos ${ }^{83}$ y en 16,7 - un texto redaccional, como hemos visto- nos dice explícitamente que el resucitado vuelve a llamar a sus discipulos y a Pedro y les encarga que vayan a Galilea, donde ellos lo "verán."

La interpretación de los textos, por tanto, debe ser más matizada. Pues Marcos no pretende con ello desacreditar a los discipulos y a la institución, sino que, más bien, aprovecha el hecho de que la comunidad ve positivamente a Pedro y a los Doce ( $i$ y más si ella hubiera acabado de presenciar el martirio de Pedro en Roma, como cree la tradición!) para dar a sus cristianos una lección que él considera muy importante y que está relacionada con lo que hemos vislo antes a propósito de las "órdenes de silencio." Es la lección de la cruz. Sólo si se está dispuesto a seguir a Jesús en el camino de la cruz, se puede entender, de verdad, quién es Jesús. Pero la comunidad parece que no lo entiende así. Le gusta más una imagen triunfalista de Jesús. ${ }^{84}$ Piensa que ya se encuentra en el camino de Jesús y no cae en la cuenta de que determinadas concepciones sobre Jesús le merecen el reproche de "Salanás" que recibió Pedro por no aceptar la cruz (cf. 8,33).

Marcos quiere hacer tambalear esta autoseguridad de su comunidad. Por esto agarra la figura de unas personas tan importantes y significativas para su comunidad, como son los Doce, y simboliza en ellas lo que le puede ocurrir a cualquier cristiano - por más bautizado que esté y ocupe el lugar que ocupe dentro de la comunidad-, si no toma conciencia de cuál es la auténtica interpretación de la persona de Jesús y no está dispuesto a seguirlo en el camino de la cruz. $85 \mathrm{Si}$ los discipulos, testigos privilegiados y escogidos personalmente por Jesús, fracasaron tan a menudo, mucho más le puede ocurrir esto a cualquier miembro de la comunidad cristiana, si no está al lado de los pobres (cf. $10,21-27)$ y no acepta la lógica del reino (cf. 3,4 ) que le llevará, como a Jesús (cf. 3,6 ), al conflicto con determinados poderes civiles y religiosos y, dado el caso, a la muerte. 


\section{La incomprensión de las mujeres}

A medida que leíamos el evangelio, Marcos nos iba desmontando todas nuestras "seguridades." Primero eran los "oficialmente piadosos" (los fariseos), los políticos (los partidarios de Herodes) y los "teólogos" (los escribas) quienes no comprendian a Jesús y querian matarlo ( $c f, 2,1-3,6$ ). Después eran los familiares (cf. 3,21) y los conciudadanos de Jesús quienes no lo entendian (cf. 6,1-6). Tampoco con el pueblo parece tener éxito Jesús (cf. 4,11s.; $15,11 \mathrm{ss}$, , aunque el que provocó su muerte no fue el pueblo sencillo y pobre, cf. 14,2). Sin embargo, al comienzo del evangelio parecia que por lo menos sus discípulos si lo entendian (c $\{$. 4,1l-13). Pero, como hemos visto, Marcos nos ha ido preparando, poco a poco, para la constatación de que tampoco fue así.

De todos modos, uno podría pensar - sobre todo leyendo los relatos en torno al sepulcro de Jesús y teniendo en cuenta que una mujer pagana ha sido presentada como modelo de le (cf. 5,34) y otra mujer como modelo de ortopraxis (cf. 14,6ss.; cf. también 12,41-44)-, que por lo menos las mujeres, quienes habian seguido a Jesús desde Galilea (cf. 15,40s.), se escapaban de la debacle general que el estilo de vida del crucificado y, sobre todo, su muerte en la cruz, provocó entre sus seguidores. De hecho, ellas son las únicas que, según Marcos, se encuentran cerca de la cruz - aunque miren de lejos (cf. 15,40). Ellas, también, son los testigos de la sepultura de Jesús (cf. 15,47) y quienes el domingo, de madrugada, se dirigen al sepulcro del Maestro (cf. 16,1), donde reciben - iy son las primeras que la reciben! $!^{86}$ - la revelación divina de la resurrección de Jesús (cf. 16,5-7).

Parece, por tanto, que al menos con ellas se podrá identificar la comunidad cristiana, dado su papel positivo. Pero con un procedimiento dramático, muy propio de Marcos, incluso ellas - iy después del anuncio de la resurrección! - no serán capaces de comprender bien el mensaje pascual que -y ello no es una casualidad - ha dejado resonar los motivos del "Nazareno" y del "crucificado" (cf, 16,6). Pues la huida de las mujeres en 16,8a recuerda al lector la huida de los discipulos que Marcos ha narrado poco antes (c). 14,50; tambièn 14,S/s.). Y su silencio (c $\int .16,8 \mathrm{~b}$ ) muestra que no han comprendido el significado de la resurrección de Jesús, el crucificado, y la tarea que Dios les confió como testigos del itincrario de la pascua. Esta incomprensión ya eslaba preparada narrativamente por cl hecho de que, según 16,1-4, querian ir a ungir el cadáver de Jesús -un notivo posiblemente redacciona ${ }^{87}$ que resulta un poco absurdo y revela, para Marcos, la incomprensión de las mujeres ${ }^{88}-y$ porque buscaban entre los muerios al que vive y se revela en Galilea, olvidandose de la palabra de Jesús que habia anumciado varias veces su resurrección (cf. $8,31 ; 9,31: 10,34 ; 14,28)$, asi como la observación de Jesús, en casa de Simón el leproso, de que la mujer había ungido su cuerpo para la sepultura (cf. 14,3ss.).

¿Cuál es, pues, el signilicado del silencio de las mujeres al final del evangelio? Me parece que ahora queda bastante claro: Marcos quiere mostrar, con ıodos los medios a su alcance, hasıa qué punto resulta dificil de comprender la vida y obra de Jesús de Nazaret. El silencio de las mujeres es, al final del evangetio, un recordatorio que quiere hacer lambalear las concepciones triunfalis- 
tas de sus cristianos y el "orgullo" de quienes tenemos siempre el peligro de olvidar la paradoja radical y la novedad siempre escandalosa de la revelación cristiana. ${ }^{89}$

\section{La cruz, climax de la obra de Marcos}

Después de lo que acabamos de constatar, ya no nos puede sorprender que el tilulo por excelencia que Marcos aplica a Jesús, el litulo de "Hijo de Dios" (cf. $1,1.11 ; 9,7$; cf. también 3,$11 ; 5,7$ ), ${ }^{90}$ sólo se encuentra una vez, según Marcos, en boca de un hombre y que en este lugar no haya ninguna "orden de silencio" o algo parecido, que pueda poner sordina a este título. Me refiero al texto de 15,39, donde un centurión pagano, al pie de la cruz, viendo cómo Jesús ha expirado - Marcos ha presentado la muerte de Jesús en coda su dureza, pues Jesús muere gritando/rezando (cᄃ. Sal. 22,2) “ „Dios mio, Dios mio! ¿por qué me ha abandonado?" $(15,34)^{91}$ — confiesa: "Verdaderamente este hombre era Hijo de Dios"' (15,39b). Al pie de la cruz se puede confesar, con toda libertad, que Jesús es el Mesías, el Hijo de Dios, ${ }^{92}$ pues en este lugar los títulos no dan pie ya a equivocos triunfalistas.

$Y$ dada la crítica radical a la cual Marcos ha sometido la religiosidad tradicional judia -y con ello quiere poner sobre aviso a la religiosidad tradicional cristiana, la cual corre el peligro de limarle las aristas al mensaje radical de Jesús para evitar asi el conflicto con los poderes fácticos de nuestro mundo egoista-, no debe sorprendernos tampoco, que ponga esıa confesión en labios de un pagano. Pues un personaje así simboliza a quien sabe que no tiene derechos especiales por ser miembro del pueblo de Dios. Un personaje así no puede autoengañarse, pensando que conoce bien a Dios, porque ha recibido la revelación del A.T. Por otro lado, no es casual que el pagano lenga acceso a la fe precisamente al pie de la cruz. Pues con la muerte de Jesús en la cruz "el velo del santuario se rasgó en dos, de arriba abajo" $(15,38)$, lo cual simboliza que acabó ya la Antigua Alianza ${ }^{93}$ y empieza la misión cristiana de los paganos. 94

Lo que acabo de decir viene confirmado por la escena que precede inmediatamente a la confesión del centurión pagano, que forma un contraste con ésta. Por un lado se recoge el motivo de que la crítica de Jesús al templo llevó a Jesús a la cruz (cf. 15,29b). Por otro lado se contrapone la concepción triunfalisıa de Dios, la cual espera de Dios y de Jesús que actúe a lo superman bajando de la cruz - y exige este tipo de acciones "milagrosas" para poder creer en Jesús: "¡El Cristo, el Rey de Israel!, que baje ahora de la cruz, para que lo veamos y creamos," gritan los sumos sacerdotes y los escribas en 15,32 (cf. 15,31 y 15,29s.) -, a la concepción de la comunidad cristiana, que descubre en la impotencia del amor del que da su vida por nosotros la revelación máxima del poder amoroso de Dios. 


\section{Conclusión}

Después de todo lo que acabamos de ver, tanto a propósito de la esiructura del evangelio, como de los retoques y acenıos redaccionales que Marcos ha puesto en las diversas Iradiciones cristianas que incorporó al evangelio, podemos constatar que hay como un hilo conductor que atraviesa toda la obra. Me refiero a la cruz de Jesús. L a sombra de la cruz, que aparecia ya claramente en 3,6, se proyecta continuamente sobre todas las Iradiciones que Marcos recoge en su obra. Y esta sombra de la cruz no solo nos ayuda a descubrir quic̀n ess Jesús, sino también quièn es el discipulo auténtico. En Marcos queda bien patente que si el discipulo no está dispuesto a seguir a Jesús en el camino de la cruz, no será capaz de comprender, de verdad, quién es Jesús. O dicho con otras palabras: sólo el que sigue a Jesús en el camino que lleva a la cruz liene la auténtica confesión mesiánica.

Esta realidad es la que me ha llevado a dar a mi trabajo el título: "Marcos - la corrección de una ideologia triunfalista." Si Marcos ha puesto unos acentos tan claros y concretos en su obra, ello se debe a que creeria que tenia que corregir aquellos elementos de la cristología y de la eclesiologia de su comunidad, que favorecian una concepción demasiado Iriunfalista de la ligura de Jesús, olvidando la realidad conflictiva de lo que fue la vida real de Jesús de Nazaret. Pero ello no significa, para Marcos, que el camino del cristiano, en cuanto camino de la cruz, sea un camino que esté marcado por el desaliento y la desesperanza. Todo lo contrario. En este camino, que es también el camino del resucitado, se encuentra sembrada una profunda esperanza, una esperanza que he visto brillar en la inmensa bondad de la gente pobre y sencilla de El Salvador que sabe, con una fe inmensa, que el amor inmenso de Dios, que se refleja en su amor y en su compartir la vida con los demás, es, a la larga, más fuerte que los idolos de muerte que la amenazan. Saben que, por un lado, Jesús les precede en el camino que lleva a la cruz, como precedió a sus discípulos camino de Jerusalén (cf. 10,32), y, por otro, saben también que les precede en el camino de la resurrección y que no están solos y abandonados en este camino de Galilea. Tienen la promesa de Jesús de que irá siempre delante de ellos y que allí lo verán (cf. 14,$28 ; 16,7$ ). Tienen tambièn la vida de Jesús que les sirve de polo de orientación y de fuente de esperanza (su fe en la palabra de Dios es inmensa). Y como en el camino del seguimiento de Jesús no les será ahorrada la persecución, tienen también el Espiritu Santo, fuente de amor inagotable, que les dará fuerzas y les inspirará qué es lo que deben decir cuando sus adversarios los lleven ante los tribunales (cᄃ. 13,11). Por eso para ellos, que son los auténticos destinatarios de obras como la de Marcos el evangelio es, sin duda, una "Buena Noticia"' (Mc. 1,1).

\section{NOTAS}

1. Cf. ECA, 1980, 379, 492.

2. "Marcus eum subsecutus tamquam pedisequus et breviator eius videtur," "De consensu evangelisıarum I,2 (CSEL 43,4). 
3. CJ. R. Pesch, Das Markusevangelium, 2 vol. (Freiburg, ${ }^{3} 1980$ y ${ }^{1}$ 1977), Vol. I, p. 30s. E5to lleva consigo que el autor esté más cerca - en el tiempo- del Jesús histórico que el resto de los evangelistas sinópticos. J. Roloff ha insistịdo, con razón, en Das Markusevangelium als Geschichtsdarstellung, EvTh 27 (1969) 73-93, sobre la importancia que la historia de Jesús tiene para Marcos, y en su obra Das Kerygma und der irdische Jesu (Gotlingen, 1970) critica a los autores de la escuela denominada "historia de las formas" porque acentúan dernasiado el aspecto kerigmático de las tradiciones evangélicas; cf. tambièn Pesch 1.c. 148.54 y G. Theissen, Urchristliche Wundergeschichren (Gülersloh, 1974) pp. 273.

4. Al menos esia es la hipótesis que me parece que explica mejor las semejanzas y las diferencias que eneonıramos en los tres evangelios sinopticos: cf. P. Achtemeier, Mark (Philadelphia, 1975). p. 7. Sobre las vellajas y las dificultades de la teoria denominada "de las dos fuentes," cr. K. Haacker, Neutesramemliche Wissenschaft (Wuppertal, 1981), pp. 44-47; G. Strecker -U. Schnelle, Einführung in die neusestamentliche Exegese (Gottingen, 1983), pp. 44.61.

5. Sobrc este método cf. J. Rolde, Die redaktionsgeschichtliche Melode (Hamburg, 1966). El autor clásico que aplicó este método a Marcos fue W. Marxsen, El evangelisła Marcos (Salamanca, (981).

6. Como habian sostenido los autores clásicos del método denominado "historia de las formas:" cf. K.L. Sclımid, Der Rahmen der Geschichre Jesu (1919, reimprimido en Darmstadt en. 1969); M. Dibelius, Die Formgeschichre des Evangeliums (Tübingen, 1919); R. Bultman., Die Geschichle der synoprischen Tradition (Berlin, 1921). Sobre este mélodo of. K. Koch, Was ist Formgeschichre (Neukirchen-Vluyn, ${ }_{1974) .}$

7. Desde este punto de vista resulta muy interesante e iluminadora la obra de D. Michie y D. Rhoads, Mark as Story. An Introduction to the Narrative of a Gospel (Philadelphia, 1981).

8. Por ello F. Belo escogió precisamente este evangelio e intentó interpretarlo con ayuda del méIodo materialista en su obra Lectura maserialisio del evangelio de Marcos (Esiella, 1975).

9. Esto no excluye, evidentemente, que las tradiciones recogidas por los redactores de los evangelios puedan tener un fundamento histórico. Sobre el problema que plantea el Jesús historico, cf. la interesante obra de Ch. Perrot, Jesús y la historio (Madrid, 1982). Achtemeier I.c. 17-21 explica los pasos que hay que dar para poder llegar hasta el nivel histórico de las narraciones.

10. Marcos es el único evangelista que pone a su obra el título de "evangelio" $(1,1)$. Como forma literaria es, fundamentalmente, una creación cristiana. Para Marcos, el relato de la vida terrena de Jesús, de su predicación, pasión y resurrección, es un mensaje gozoso y de victoria, que haciendo presente a Jesús en medio de la comunidad, realiza la salvación. Sobre el significado de la palabra "evangelio" en Marcos, cf. Marzsen, l.c., III-143; cf. también J. Gnilka, Das Evangelium nach Markus, 2 vol. (Zürich-Neukirchen/Vluyn, 1978 y 1979), vol. I, pp. 17-24.

11. Esta constatación ha obtenido carta de ciudadanía en la exégesis católica desde la enciclica de Pio XII Divino afflante spiriu y con la constitución Dei Verbum del Concilio Vaticano II. Sobre el modo como podemos leer hoy la Biblia, vale la pena leer la obra, eserita con claridad y pedagogia, de G. Lohfink, Ahora entiendo la Biblia (Madrid, 1977).

12. Cf. tambien en este sentido la obra de G. Reploh, Markus - Lehrer der Gemeinde (Stuttgart, 1969), sobre todo las conclusiones en las pp. 228-231.

13. Históricamente resulta difieil saber con certeza cómo era e incluso dónde vivia la comunidad a la que Marcos dedicó su obra. Muchos autores han creido que escribió en Roma (cf. p. ej. G. Minette de Tillesse, Le secret messianique dans l'evangile de Marc (Paris, 1968), pp. 435437. Pero ni la tradición en que se apoyan (el testimonio de Papias hacia los anos 120-130, recogido por Eusebio en su Hist. Eccl. III 39,15, según el cual el evangelio habria sido escrito por Marcos, el secretario e intérprete de Pedro, de acuerdo con lo que recordaba de la predicación de Pedro), ni los indicios que encontramos en el texto, permiten afirmarlo con absoluta certeza (cf. Pesch I.c., I, 12-15; Gnilka, 1.c., I, 32-35; Achtemeier, 1.c., II4s.).

14. Un análisis literario y teológico de los textos, realizado con la ayuda de los métodos hermenéuticos modernos, permite averiguar hoy con cierta garantla cuáles son los acentos que Marcos puso en su obra: cf. en este sentido, Gnilka, 1.e., 1, 25-32; Achtemeier, 1.c., 15s. 2230. 
15. Asi lo interprela, por ejemplo, L. Schenke, Die Wundererzbhlungen des Markusevangeliums (Stuttgart, 1974), pp. 396-416).

16. $C$. lo que dijimos supra nota 13. En español puede verse tambitn lo que indice $\mathbf{E}$. Lohse, Introduccion al Nuevo Testamento (Madrid, 1975), pp. 147.149.

17. Marcos tuvo mucha libertad, gracias al hecho de que fue el primer evangelista, en la estruciuración de su obra, que revela asi claramente su intención teologica. Con todo, la secuencia Sundamental, (vida)-muerıe-resurrección de Jesús esıaba preparada por el kerigma cristiano primitivo y por la narración premarcana de la pasión. Cf. Achtemeier, I.c., 22-26, quien subraya tambien que la estructura es una buena clave de lectura del evangelio de Marcos, pues es una estruclura leológica y no hisıórica (cf. lambién I.c., 14-IS).

18. El primero que llamó la aıención sobre este hecho, estudiándolo de modo sistemático, fue $\mathbf{W}$. Wrede en su obra clásica, hoy superada, Das Messiasgeheimnis in den Evangelien (Goutingen, 1901). Sobre este punto vale la pena consultar la obra de Minette de Tillesse citada en la nota 13. Cf. lambitn E. Schweizer, Zur Frage des Messiasgeheimnisses bei Morkus, ZNW 56, (1965), 1-8; U. Luz, Das Geheimnismoriv und die markinische Chrisıologie, ZNW 56, (1965), 9-30. En cambio Pesch, I.c., Il, 36-47, detiende la teoria, sin que sus razones me parezcan convincentes, de que el "secreto mesiánico" no tiene nada que ver con la labor redaccional de Marcos y que, por tanıo, no sirve para iluminar la teologia del redactor. Pesch se basa mucho en la obra de H. Ruisănen, Das 'Messiasgeheimnis' im Markusevangelium (Helsinki, 1976), quien, con todo, defiende una postura algo más matizada: según el, sólo las órdenes de silencio a los demonios y a los discipulos forman parte del "secreto mesiánico" redaccional (el motivo de la incomprensión de los discipulos estaria relacionado con él).

19. Empiezo queriendo dilucidar cuâl es la estructura lógica que Marcos debió dar a su obra, porque en este campo pudo gozar de bastante libertad. En cambio no tenia tanta libertad cuando retocaba las Iradiciones que el habia recibido, pues se trataba de tradiciones muy venerables. Ultimamente subrayan los especialistas, con razón, que Marcos era, en el fondo, un teólogo "tradicional" quien queria conservar en su justo valor las tradiciones recibidas (cf. Gnilka, 2.C., I,25; cf. también Raistnen, I.c., 167s. y la obra de Pesch, antes mencionada, teniendo en cuenta que este autor acentúa excesivamente este aspecto).

20. Como se sabe, las estructuras y divisiones propuestas por las tradiciones modernas de los evangelios -y lo mismo vale para las separaciones y puntuaciones propias de las ediciones criticas del texto griego de Marcos- no son obra del evangelista, sino posteriores. Los papiros y manuscritos más antiguos tienen el texto escrito en letras griegas mayúsculas y sin separaciones de letras ni signos ortográficos. Pero esto no significa que para Marcos -y para los lectores/oyentes de su evangelio, que estaban habituados a este lipo de escritura - la obra no tuviera una estructura interna bien definida. Precisamente esta es la que queremos desentrañar aquí.

21. Según. B. Maggioni, El relato de Marcos (Madrid, 1981), p. 10: "Son las dos caras del mismo misterio." "Marcos no se contenta con ir revelando poco a poco el misterio cristiano; se preocupa al mismo tiempo de llevar al lector a que descubra sus propios temores, su propia ignorancia, su propia resistencia. Por eso el evangelio se mueve en dos llneas paralelas: la revelación del misterio de Jesús y la manifestación del corazón del hombre. Esta continua confrontación entre los dos aspectos es la que convierte a Marcos en un evangelio actual, dramático e inquietante" (ibid.).

22. Marcos subraya la responsabilidad de los ancianos, escribas, fariseos y partidarios de Herodes en la muerte de Jesús: cf. 3,6; 8,31; 10,33; 11,18; 11,27 con 12,12; 12,13; 14,1s.10s.43.55ss; 15,1ss.10s.31.

23. Cf. J.M. Robinson, Das Geschichtsversıundnis des Markusevangeliums (Zurich, 1956), p. 103.

24. Cf. Achtemejer, 1.c., 71s. La insistencia de Marcos en los exorcismos no es casual. Marcos quiere mostrar a su comunidad, la cual era perseguida, que si se sitúa en la linea de Jesús de Nazaret, podrá vencer también, como èl, las fuerzas del mal, que fueron derrotadas ya fundalmentalmente por Jesús.

25. El motivo del reinado de Dios en el A.T., en cuya tradición, sobre todo profetica, se encuentra Jesús, comportaba fundamentalmente una accion gratuita de Dios que significaba un cambio en la esiructura y en la lógica egolsta del mundo, a fin de que los pobres y marginados de la tierra obtengan la liberación y la justicia a la que tienen derecho, de modo que surja una 
sociedad auténticamente fraternal y humana, en la que no haya pobres ni oprimidos, porque no hay ya empobrecedores ni opresores. Jesús anuncia aqui el fin de una sociedad basada en la lógica de la equivalencia, del provecho propio y del dominio de unos sobre otros, mostrando, con su palabra y con su obra, que es posible y deseable una sociedad basada en la lógica de la generosidad, del amor gratuito y del servicio. Este mensaje ienis que resultar escandaloso a quienes creen que una sociedad conformada por estos principios no tiene futuro. $Y$ pueden creerlo sin dificulıad, porque no sufren en carne propia los efecios aniquiladores $y$ deshumanizadores de la pobreza e injusticia que palpan día a dia los desheredados de nuestra tierra.

26. En la misma linea se encuentra su critica a las leyes de la pureza en Mc. 7, que es el bloque central de controversias en nuestro evangelio.

27. Es importante para mi interpretación notar que la obra original de Marcos terminaba en 16,8. L.os vv. 9-20 son, sin duJa. sunónicos, pero no fueron escritos por el redacior del evangelio, como hoy dia está generalmente reconocido (cf. la nota de la Biblia del Jerusalén sobre cstos versos (Bilbao, 1967), p. 1.366). Los estudios de K. Aland, Der wiedergefundene Mar. kusschluss? Eine methodologische Bemerkung zur lexikririschen Arbeit, ZThk 67 (1970) 3-13 y Der Schluss des Markusevangeliums, en M. Sabbe, ed., L'évangile selon Marc. Tradition et rédaction (Gembloux/Leuven 1974), pp. 435-470, asi como la tesis doctoral de J. Hug, La finale de l'évangile de Marc. Mc 16,9-20 (Paris, 1978), resultan convincentes en este punto. En cambio, a A. Benito estos vv. le parecen oríginales: cf. su argumentación, poco convincente, en Marcos 16. Redacción y hermenéutica, Salmanticensis 24 (1977) 297-305.

28. Entre 8,21 y 8,27, 8,22-26 es claramente una pericopa de transición, como veremos luegohay una cesura radical que divide en dos el texto de Mc. Cf. con todo las criticas que hace Achtemeier, 1.c., 36-38, a esta manera de dividit el texio. Según él, 1.c., 38-40, no se ha encontrado aún la solución adecuada al problema.

29. Se discute por motivos de critica textual si el titulo "Hijo de Dios" que encontramos en Mc. 1,1 , es original o no de Marcos. Se pueden ver los argumentos en pro y en contra en Minetie de Tillesse, I.c., 353; Gnilka, 1.c., I,43; Pesch 1.c., 1, 74,n. a; R. Travijano, Comienzo del evangelio. Estudio sobre el prólogo de S. Marcos (Burgos, 1971), pp. 75. Personalmente me inclino a creer que las palabras son originales.

30. Para la estruclura que propongo me he inspirado en E. Schweizer, Die theologische Leistung des Markus, EvTh 24 (1964) 342-355 (condensado con el titulo "La aportación teologica de Marcos" en Selecciones de Teologia 9 (1970) 50-61), teniendo en cuenta las observaciones de I. de la Potterie, "De compositione Evangelii Marci," Verbum Domini 44 (1966) 135-141 (en este autor se pueden leer las ventajas y los inconvenientes de otras posibles estructuras de Marcos, por ejemplo (la estructura según el espacio); cf. tambien J. Delorme, El evangelio seguin san Marcos (Estella, 1977). p. 33, y D.A. Koch, Inhaltliche Gliederung und geographischer Aufriss im Markusevangelium, NTSt 29 (1983) 145-156, quien distribuye en tres grupos las estruciuras que los investigadores han propuesto (de acuerdo con el principio es(ructurador): a) geográfico; b) temático; c) mixto (un compromiso entre los dos anteriores). Para una propuesta de esiructura en la cual, aun reconociendo que la theologia crucis está en el centro de la perspectiva de Marcos, se destacan más, sin embargo, otros aspectos como la pascua o el ministerio terreno de Jesús (que son esenciales también en mi interpretación), cf. V. Fusco, Parola e Regno. La sezione delle parabole (Mc 4, 1-34) nella pros. pelliva marciana (Brescia, 1980), pp. 114-132.

31. L.as palabras del v. 116 "Tú eres mi Hijo amado, en ti me complazco" son una mezcla de dos lexıos del A.T.: Sal, 2.7; Is. 42,1. El texio de lsaias se refiere al Siervo de Yahvé (cr. Gnilka, l.c., 1,50 ). La tradición premarcana de la pasión explicaba -y Marcos conservó este rasgoel destino de Jesús con ayuda del motivo del justo que sufre.

32. Según el A.T., sólo Dios tenia poder sobre las aguas del mar (cf. Sal. 107, 23ss.; 104,7; Jonás 1). También el perdonar pecados es algo exclusivo de Dios (cf. Mc. 2,7).

33. En 3.11 los demonios llaman a Jesús "Hijo de Dios" ( $c \digamma$. también 5,7), pero Jesús les prohibe que lo digan (er. 3,12).

34. Este aspecto lo desarrollo más ampliamente en la segunda parte del artículo a propósito del motivo marcano de la incomprensión de los discipulos. Según los especialistas, 8,17-21 es un lexio redaccional. Por ello resulta particularmente significativo para poder conocer la preocupación teológica de Marcos. Achtemeier observa con razón: If there is any progression in 
the picture Mark paints of the disciples, it appears to be from bad 10 worse (1.c., 92). Resulta interesante notar, al final de la primera parte de la estructura, que los indicios literarios confirman la esiruciura teológica. En efecto, cada una de las tres secciones empieza con un sumario (1,14s, 3,7-12;6,6b). Sigue, a continuación, una pericopa de vocación o misión de los discipulos (1,16-20: 3,13-19;6,7-13). Marcos pone luego una actuación de Jesús con poder y la reacción que ella provoca $(1,21-3,5 ; 3,20-5,43 ; 6,14-8,13)$. Por último, cada sección concluye con la constaiación de la ceguera -empezando por los enemigos y acabando por los amigos- que dicha aciuación de Jesús provoca (cf. 3,6; 6,1-6a; 8,14-21).

35. Cr. Gnilka, I.c., I, 222 nola 16.

16. Se puede ، decir, empleando una formulación de $M$. Kahler, que Marcos es "una pasión con una introducción detallada."

37. Basia una ujcada a la estruciura del fragmenio, enmarcado por dos curaciones de ciegos, que tience un profundo significado simbólico, para convencerse de ello (cf. 8,22-26 y 10,46-52). En todo caso, no hay duda de que 8,27-10,45 revela claramente la mano del redacior: cf. $E$. Manicardi, I/ cammino di Gesunel Vangelo di Marco (Roma,1981), p. J10: cf. lambien Achtemeier, I.c., 82-91, quien, recogiendo los resulıados de las investigaciones, principalmente alemanas y norteamericanas, sobre este punio, subraya que incluso a partir de 11,1 hay una notable impronta redaccional en los textos. En cambio Pesch, 1.c., 30, cree, equivocadamenle, que 8,27-10,52 es un fragmento premarcano que formaba parte de la fuente de la pasión que Marcos recibió (las opiniones de Pesch sobre la extensión y el significado de la fuente premarcana de la pasión que desarrolla, por ejemplo, en I.c., 11, 1-27, me parecen muy poco convincentes).

38. Sobre el significado del camino en Marcos ver la obra, de Manicardi citada en la nota 37. Según dicho autor el camino parece un elemento tipico de la redacción de Marcos (cf. I.c. 14 y 45).

39. Asi lo interpretan algunos autores y podria ser una explicación al nivel histórico de los textos (de hecho, en la pasión nota Marcos, a partir de la entrada de Jesús en Jerusalén, que este no se queda nunca a dormir en Jerusalén y que lo prenden, a trajción, cuando se encontraba en Getsemani), pero resulta insuficiente al nivel literario-teológico en el que Mareos se silua.

40. Ver lambién I,11; 9,7 y 15,39. Entre los litulos de Mesias e Hijo de Dios hay un paralelismo, como puede verse en la confesión cristiana primitiva que encontramos en Rm. 1,3-4 (cf. H. Zimmermann, Los méiodos hisı́́rico-críricos en el N.T. (Madrid, 1969), pp. 206-218.

41. Este motivo lo ha encontrado ya Marcos en la fuente de la pasión que él utiliza: cf. Pesch, 1.c., II, 13s.; Gnilka, 1.c., II, 15s.

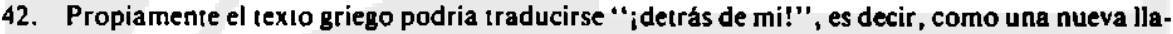
mada a Pedro a que siga a Jesús, en un camino que es esencialmente el camino de la cruz: cf. Pesch, I.c., II, 54.

43. Los textos los ha encontrado Marcos en la tradición, pero es el quien los sitúa aqui, a continuación de la incomprensión de los discipulos.

44. La importancia de estos versiculos viene subrayada por $8,37-9,1$, un texto que remarca la trascendencia y el significado de las palabras de Jesús sobre el seguimiento en el camino de la cruz.

45. "En el camino" se encuentra en 8,27 y en 10,52 , de modo que forme una inclusion de lodo el fragmento y serhale la unidad profunda que éste tiene en Marcos. La fórmula aparece tam. bien en 9,33.34: 10,32. "El camino" sale también en 10,17.46.

46. El texio subrayado por mi es una cita de Is. 53,10 , un texto que hace referencia al Siervo de Yalıvé. Cr. Gnilka, I.c., Il, 103s.; Pesch, 1.c., ll, 162s.

47. Cuando analicemos el motivo del "secreto mesiánico" en la segunda parte del arlículo, veremos que es efectivamente asi.

48. En este fragmento se encuenıra tambièn sólo un exorcismo (cf. 9,14-29). También a propósito de él coinciden los especialisıas en que Marcos quiere dar aqul una instrucción especial a su comunidad la cual, probablemente, se veia confrontada con el hecho de que ya no conseguia expulsar a los demonios: cf. Pesch, 1.c., 11, 97.

49. Una lectura sinóptica de los textos de la pasión lo muestra claramente.

50. En este sentido, es muy interesante la obra de Minette de Tillesse citada en la nota 13.

51. Marcos no tiene ni el material de Q que encontramos en Mateo y en Lucas, nj los grandes discursos de Juan. Los milagros en el -al igual que la pasión- ocupan una quinta parte de su 
obra. Sobre los milagros en Marcos, cf. K. Kertelge, Die Wunder Jesu im Markusevangelium (Munchen, 1970); Schenke, 1.c.; Minette de Tillese 1.c., 39-73; Gnilka, 1.c., I, 221-226.

52. Por ejemplo en la tempesiada calınada (cf. $4,35-4 \mathrm{I}$ ) leemos que Jesús esıba durmiendo "en popa" "sobre un cabezal" (v. 38). Pero los detalles de este tipo no son indicio de historicidad, sino fruto de la narración popular. Sobre la historicidad de los milagros en Marcos ver Gnilka, 1.c., 1, 225s.

53. Esto viene confirmado también por las fórmulas poco precisas con que empiezan muchas narracciones: ef. 1,$40 ; 3,1 ; 7,32 ; 8,22 ; 9,14$, ecc. Cf. E. Schweizer, Das Evangelium nach Morkus (Goltingen, 1968), p. 9.

54. También el curar a un leprosu era considerado como una obra extraordinaria, parecida a la resurrección de un muerio: $c \Gamma$. Pescl, $1 . c ., I, 141$. La resurrección de la hija de Jairo (cr. $5,21-43$ ) revela cómo Jesús supera los imilagros de los profelas Elias y Eliseo (cf. IRe.17; 2Re.4); en Jesús que anda sobre las aguas (cf. 6,50) puede descubrirse una epifania de Yahvé (cf. Pesch, 1.c., 1,2795.).

53. Cr. Schweizer Das Evangelium 7. Es verdad, con todo, que en Marcos se encuentran aún algunos elementos de esie tipo, que estaban en la tradición premarcana y que el redacior ha conservado: $c f$. las manipulaciones de Jcsús en 7,33 y 8,23, o bien las fórmulas "misteriosas" (en lengua extranjera: Marcos las conserva, pero las traduce a continuación!) ralita, qum $(5,41)$ y efala $(7,34)$. Sobre el significado de la fe en los milagros de Marcos, ver $X$. Alegre - L. Tuñi, "Los milagros en Marcos: icritica a una religiosidad triunfalisia?," Sal Terrae 62 (1974) 445s.

56. Marcos - al igual que los otros evangelistas - no emplea nunca la palabra teras "prodigio" para denominar los milagros, sino que utiliza la palabra dynamis que significa "fuerza," "poder:" cf, 5,30; $6,2.14$ y lo que indica Kertelge 1.c., 120s. Sobre la tradición de los milagros, cf. la exposición clásica de Bulımann, I.c., 6 1964, pp. 223-260.

57. Sobre esla figura ver la obra clásica de $L$. Bieler, Theios anerr. Das Bild des 'gortlichen Menschen' in Spdtantike und Frithehristentum (Wien, 1935 y 1936), leniendo en cuenta las observaciones crlticas que le hace M. Smith, Prolegomena to a Discisssion of Aretalogies, Divine Men, the Gospels and Jesus, JBL 90 (1971) 174-199. Sobre este punto ver tambien H. W. Kuhn, Ältere Sammlungen im Markusevangefium (Goulingen, 1971), pp. 194s (cf. lambien 191-197; 204-206; 211ss); D.E. Keck, Mark 3,7-12 and Mark's Chrisiology, JBL 84 (1965) 341-358; T.E. Weeden, The Heresy ihat Necessitated Mark's Gospel, ZNW 59 (1958) 145-158 (pero sobre la interpretación que da este autor, cf. lo que digo infra nota 82).

58. Cf. Kuhn, I.C., $194 \mathrm{~s}$.

59. Cr. W. Von Martitz, újbs thw VIII 334-340; O. Betz, "The Concept of the so-called 'Divine Man' in Mark's Christology," en D. Aune (ed.), Studies in New Testament and Early Christian Literalure (Leiden, 1972) 229-240; D.L. Tiede, The Charismatic Figure as Miracle Worker (Missoula, 1972), sobre lodo las pp. 238-240 y 241-292; E. Schweizer, Neuere Markusforschung in USA, EvTh 33 (1973) 535s; D.H. Koch, Die Bedeurung der Wundererzdhlungen filr die Christologie des Markusevangeliums (Berlin, 1975), p. 26 nola 3 (pero cf. lo que indica en la p. 124 nora 52); Pesch, I.C., I, 55-59. 279-281. Cr. tambien la postura más manizada de Theissen 1.c. 2625s. 268-273.

60. Cf. Pesch, 1.c., 1, 48ss. Kuhn, 1.c., 218-225 subraya que Marcos quiso corregir la concepeión gloriosa de los milagros propios del "hombre divino" relacionándola, sobre todo, con la pasión. Ello no puede significar, como nola con razón Theissen, 1.c., 287ss (cf. lambién Koch, 1.c., $18-193$ ), una relativizacion total de los milagros por parie de Marcos, como si ésie los viera negativamente; lo que Marcos quiere evitar es que los milagros sean vistos aisladamente sin el conırapeso de la pasión (cf. Theissen, l.c., 29); cf. tambien S. Schulz, Die Siunde der Bolschaft (Hamburg, 1967), pp. 64-79, sobre lodo 715s. Sobre la aportacion teologica de Marcos cf. tombien Alegre- TuAi, I.c., 447 s.

61. Este aspecio lo ha desarrollado, con razon, Pesch en su comentario al evangelio, antes citado, pero lo ha acentuado excesivamente a costa de la labor redaccional del evangelista.

62. La demostración de este punio puede encontrarse en la magnífica obra de Minelle de Tillesse antes mencionada.

63. Por lo menos el molivo del "silencio" es redaccional, como nota Kerıelge, 1.c., 31ss.

64. Esto no excluye que Marcos haya podido encontrar, a veces, este motivo en la Iradición. Por ejemplo la orden dada por Jesús al demonio "calla y sal de él" $(1,25)$ podría ser tradicional, 
pues forma parte de la iecnica clásica de los exorcismos, en los cuales el exorcista obliga a callar al demonio que inientaba dominar al exorcista pronunciando su nombre (cf. Pesch, I.c., I, 121-123). Pero el hecho de que en dos sumarios redaccionales se encuentra lambićn la orden dada a los demonios de callar "pues le conocian" (cf. 1,34) y no queria que revelaran que era Hijo de Dios (cГ. 3.11s.), demuestra el interés del redacior por este motivo. Asi lo interpretan también Minette de Tillesse, 1.c., 249-251; Grilka, I.c., 1, 85s. 133.167-170. Sobre la interpretación distinıa que da Pesch ver supro noı 18.

65. Aparie de la bibliogralia citada supra en la nola 27, puede verse ahora sobre este punto del final original de Marcos, mi estudio: $X$. Alegre, Un silenci elogilent: o la paradoxa del final de Marc: "I no digueren res a ningú parque tenien por" (Mc 16,8b) (Barcelona, 1984), donde analizo el significado de este hecho.

66. Cr. E.L. Bode, The First Easter Morning. The Guspel Accounts of the Women's Visit to the Tomb of Jesus (Roma, 1970), pp. 35-37; J. Kremer, Die Osterevangelien - Geschichren um! Geschichre (Stutıart, 1977), p. 46; Gnilka, I.c., II, 338; W. Grundmann, Das Evangelium nach Markus (Berlin, 31965), p. 321, a propósito de 16,7. Sobre el hecho de que lambièn 14,28 es redaccional, cf. Gnilka, I.c., II, 25 Is. y 258 (alli puedell verse otros autores que son del mismo parecer). En cambio Pesch, 1.c., I, 13 y 11,382 sostiene que esıos texios son de la tradicion. Tambien D. Dormeyer, Die Passion Jesu als Verhallensmodell. Tradirions- und Redaktionsgeschichte der Markuspassion (Munsıer, 1974), pp. 226-229, cree que 16,7 (como lambién 16,8b) es un texto Iradicional, pues formaria parte del esquema clásico de las teofanias. Pero las razones que dan ambos autores no me parecen suficientemente convincenles.

67. La mayoria de los Iexios que hablan de Galilea son redaccionales (c $f$. Gnilka, 1.c., 1,70). Sobre el significado de Galilea en Marcos ver Pesch, l.c., 1, 104; Gnilka, I.c., 1, 69-71; Manicardi, 1.c., 190s. y la bibliografia citada por lodos ellos. E. Lohmeyer, en su obra Galilea und Jerusalem (Gottingen, 1936), sostuvo la tesis, sin convencer, de que Galilea es el lugar en el que vive la comunidad de Marcos, comunidad que estaba en oposición a la comunidad de Jerusalén (cf. también Marxsen, 1.c., 49-109, quien dedica lodo un capilulo a esludjar el marco geográfico de Marcos). Cr. también los autores citados infra en la nota $\mathbf{8 2 .}$

68. Por ello Marcos enmarca la obra de Jesús con dos lextos de vocación o llamada a los discipulos a seguir a Jesús (cf. Alegre, Un silenci, 20-22).

69. Cr. Gnilka, I.c., II, 338 (y los autores que cita); J. Schmitt, Résurrection de Jésus duns le kerygme, la tradition, la calechese, DBS, X, 533-558; P. Holfmann, art. Auferstehung Jesu Christi, TRE, 4, 498; Benito, 1.c., 283. Es importante que notemos aqui que si el texto es redaccional, revela un interés particular del evangelista. En todo caso, dado que, como vimos, el contexio inmediato anterior es redaccional (cᄃ. supra nola 27 y 65 a propósilo de 16,7 ), el versiculo adquiere, en el coniexto actual de Marcos, un significado nuevo. Si el v. 8 se hubiera enconırado ya en la tradición, habria apuntado alli a que la comunidad no cenırara su inleres en la lumba que se encontraba vacia.

70. Sobre otras explicaciones que se han inıentado sobre este silencio, of. Alegre, Un silenci, 23s., y la bibliografia que cilo alli.

71. Cr. Alegre, Un silenci, 27.

72. El contexio es una creación claramente redaccional de Marcos. Por otro lado, el procedimienıo literario de sand wich es tipico del redactor: cf. Mineule de Tillese, 52, y los autores citados por el. Tambien el vocabulario del v. 20 lleva el sello de la redacción.

73. Cf. Lc. 8,19-21: el v. 19 corresponde a Mc. 3,31; Lc. omite Mc. 3,21 y sitúa Mc. 3,22-30 en otro contexto (cf. Lc. 11,14-15.17-22; 12,10). El nuevo contexio en el que Lucas sitúa este fragmento sobre la familia (desputs del sermón de Jesús que empieza con la parábola del sembrador que ha hablado de los que escuchan la palabra de Dios y la cumplen: $c f . v$. 5) y las modificaciones redaccionales que introduce en el texto de Marcos, hacen que la perlcopa tenga en el un sentido nuevo y positivo con respecto a la familia de Jesús (suprimiendo la pregunta de Mc. 3,33 "¿Quien es mi madre y mis hermanos?" y Mc. 3,34 "Y mirando en torno a los que estaban sentados en corro, a su alrededor, dice 'Estos son mi madre y mis hermanos," suprima la contraposición que Marcos parecia establecer entre la familia de Jesús -que no le entendia (cf. Mc. 3,21) y quizás no cumplia la voluntad de Dios (cf. Mc. 3,33a)y quienes la cumplen. Como sabemos por Hch, Lucas está interesado en presentar positivamente a Marla (cf. tambien Lc. 1-2) y a los hermanos de Jesús. 
74. En el contexto de Marcos, el v. 35, más que suavizar el contraste enıre los seguidores y los parientes de Jesús (asi lo interpreta por ejemplo Gnilka, I.c., 152s.), subraya que la relación con Jesús viene dada por el cumplimiento de la voluntad de Dios que, en Marcos, viene con $/ \mathrm{j}-$ gurada por el seguimienıo de Jesús en el camino que lleva a la cruz (cf. Pesch, l.c., 1, 223)

75. Cf. R.E. Brown - K.P. Donfried - J.A. Fiızmyer - J. Reumann, Maria en el Nuevo Tesiamen10 (Salamanca, 1982).

76. Como sabemos por la historia, Santiago y los hermanos de Jesús tomaron pronto la dirección de la comunidad de Jesús.

77. Lucas suavizará estos rasgos, como acostumbra a hacerlo siempre (cf. G. Schneider), Die Passion Jesu nach den drei altesten Evangelienl (München, 1973). pp. 80-82.

78. Marcos no dice explicitamente que sean los discipulos los que protestan, pero por el contexio -y asi lo interpretan Mateo y lucas en sus textos paralelos- se ve que son ellos.

79. Cr. Pesch, I.c., I. 268 y 274.

80. Según su costumbre, Mateo y Lucas suavizaräi este reprocite de Jesús (cí. Mi. 8,26 y Lc. $8,25)$.

81. Cr. Pesch, I.c.. II, 275s: Reploh, 1.c., 75-88. Ya Wrede, I.c., 81-114, habia indicado que la incomprensión de los discipulos cra un rasgo típico de Marcus.

82. El carácter antiinstitucional de Marcos ha sido defendido muy vivamente - pero con argumentos poco convincentes- por T.E. Weeden, Mark - Tradition in Conflicr (Philadelphia, 1968). Según èl, el silencio de las mujeres en Mc. 16,8, quiere privar a los discipulos de sus credenciales apostólicas (nunca habrian enconırado al resucitado): cf. l.c, 50 y 117 . Según èl, los discipulos serian los representantes de la concepción deformada del "hombre divino" que Marcos quiere corregir con su obra (cf. I.c., 101-107). En la misma linea pueden verse los argumentos de J.D. Crossan, "Empty Tomb and Absent Lord (Mark, 16,1-8)," en W.H. Kelber (ed.), The Passion in Mark (Philadelphia, 1976). pp. I35-152 y J. Leila, El fonament irreligiós de l'església Barcelona, 1969), sobre todo a partir de la p. 119. Según J. Mateos, Los "Doce" y oiros seguidores de Jesis en el evangelio de Marcos (Madrid, 1982), los lexios de Marcos revelan que exisien dos grupos en la comunidad de Marcos - los que vienen de Israel y son llamades "los discipulos," consiituyendo un Israel mesiánico ("Doce'"), y los que no vienen de lsrael institucional (judios o no)- y dejan entrever las tensiones que existian en la Iglesia primitiva (pueden leerse sus conclusiones en las pp. 247-258); pero esia interpretación no me parece adecuada porque en ella no queda clara la intención primordial de los textos de Marcos.

83. Jesús los llama personalmente (cl. 1,16-20), los escoge para darles una larea particular y para que estén con èl (cf. 3,13-19), los entia a predicar (er. 6,7-13.30), los hace participes de una insıruccion privilegiada (cf. 4, I0ss.34; 7,17ss.; 3.3, ss.: ; en Marcos Jesús no aciúa nunca si los discipulos no están presentes!). CI. en cste sentido Achıemeier, 1.c., 92-10; Gnilka, 1.c., 1,26-28 y la critica que lace Fusco, 1.c., 145-150, de la lesis de Weeden (la manera como Fusco imerprela el inerivo de la incomprension de los discipulos se diferencia en algo de la mia: i., 1.6., 135-144). A pesar de las diferencias creo clue tanıo Marcos cono L.ucas consideran pusilivamente la figura de los Doce. Pero en la presemación que hacen de ellos ponen acenios divinıos. porque quieren que sur comunidader saqueı lecciones disıintas de ellos. Marcos guicre que la fignara de lox discipulos sirva de adveriencia a la comunidad para que no srea,

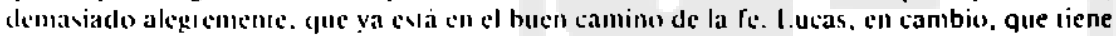
ullil comunidad gue esıa precocupada porque hau ido muriendo los primeros lestigos de la vida de Jesis - el liempo de Jesis es el "centro del tiempo:" cl. H. Conzelmann, El centro del th'min. La t'ologia de l.mes (Madrid. 1974) - y por cl criterio que les garantice que tienen las tradiciones auténticas de Jesús (cF. Lc. I, I-4), quiere presentar a los discipulos como el eslabón entre el tiempo de Jesús y el tiempo de la Iglesia y como un modelo al que la comunidad puede imilar.

84. Esıe aspecto lo destaca Reploh, 1.c., 87.231; cf. Tambien Schweizer, Das Evangelium, 220224; H.J. Steichele, Der leidende Sohn Goures. Eine Untersuchung einiger altrestamentlicher Motive in der Christologie des Markusevangeliums (Regensburg, 1980), pp. $303 \mathrm{~s}$.

85. L. Besl subraya la lecicion que lon discipulon, Fallandu, dan a la conunidad:|if a vrie wishes to talk ahom discipleship using men as exemples, there arc wo obvious approaches. He may either set forward a series of examples of gord discipleship should be followed (so Daniel I6: 2 Maccalnees: 4 Maccahces) or he mav instruct through the failures of his examples (so 
many of the stories about the patriarchs and David). Mark chose the taller course (Following Jesus. Discipleship in the Gospel of Mark (Sheffield, 1981), p. 12). Además, como nota Bcsı ibid. algunos de los miembros de la comunidad de Marcos podrian haber lallado - por ejemplo, por culpa de las persecuciones- y, en este caso, la caida de los discipulos, seguida de su perdón y de su éxito nisionero. les podia servir de acicate para su fe.

86. Es una menera de comunicar narrativamenie que Dios es, por esencia, el "Dios de la gracia" (c). Rm. 11,25-32 y X. Alegrc. Universalisme i elecció en la perspectiva del Déu de la grácia. Nores sobre els capitols $9.1 /$ de la carta als Romans, associacio biblica de Catalunya, bolctin n. 13-14, (1980), 4-12), que con la inuerte de Jesús en la cruz ha roto los moldes y los "cáleulos relipiosos" de los hombres, pues se manifiesia, no en la gloria, sino en la crus: no a los judios, sino a los paganos; no a los discipulos (hombres), sino a unas mujeres...

87. Por lo menos asi lo cree Schmilı, I.c., 533 y 558, quict considera los 5 . 3s. como redac. cionales.

88. Como indica N. Perrin, The Resurrection Narratives. A New Appoach (London, 1977), ק. 32: like the disciples, the women also fail their master (...). In the Gospel of Mark the dis. cipleship failure is total.

89. "Su desconcierto en la mañana de pascua" (se refiere a las mujeres del v. Bb) "rone fin a la evocación dramáıica, a lo largo de lodo el segundo evangelio, de la impotencia humana para peneirar el misterio revclado de Jesucrisıo" (J. Delorme, "La resurrección de Jesús cn cl lenguaje del Nuevo Testamenio, en H. Cazclles - J. Delorme - L. Derousseaux - J. le Du - R. Mace, El lenguaje de la fe en la Escriruro y en el mundo aciual (Salamanca, 1973), p. 110).

90. CC. Gnilka, I.c., I, 60-64; Maggioni, I.c., 15-17.

91. Asi lo nota con razón Steichele, 1.c., 295; cf. ıambièn 271-273.

92. Cr. Minette de Tilesse, I.c., 340 y 358; tambièn Besı, J.c., I3.

93. Esıe aspecio lo desarrolla muy bien el autor de la caria a los Hebreos (cf. a Vanhoye, El mensaje de la caria a los Hebreos (Estela, 1978).

94. Por todo lo que hemos ido viendo, ya comprendemos ahora que en Marcos no sea casual que el único hombre que confiesa en su evangelio que Jesús es "Hijo de Dios," sea precisamente un pagano. Todo el evangelio mucsıra que Jesús supera los limites judios, gracias, en úlıimo ıérmino, a que da su vida en rescate por muchos (cf. 10,45), acabando asi con la necesidad del culto de la antigua alianza. Esto fue preparado ya por la aciividad de Jesús en la Galilea de los paganos que forma inclusión con la vuelta de los discipulos a Galilea, donde se les manifestarà el resucitado. Pues "la Galilea de Marcus no tiene fronteras. En ella se oponen dos espacios: uno es el de los fariseos y leırados, que se cierra sobre si mismo; el otro es el que Jesús abre delante de si al pasar a los paganos. Marcos insiste en ello, ya que ve alli la preparación de la misión entre los paganos" (Delorme El evangelio, 145.; cf. tambièn lo que dijimos supra y la bibliografia de la nota 67; Gnilka, I.C., 323-325). 